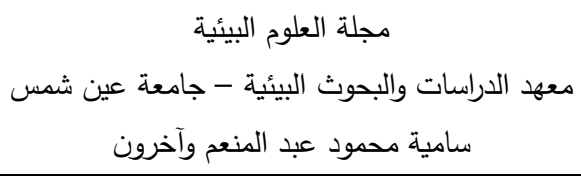

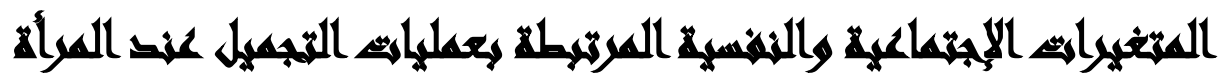

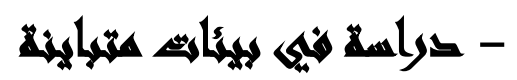

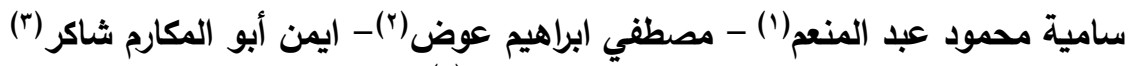

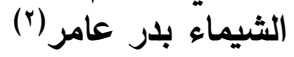

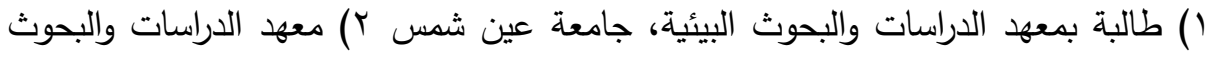

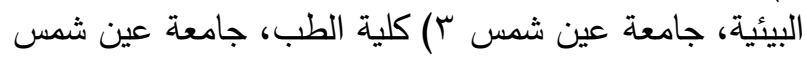

\section{المسمخلصن}

هدفت الدارسة الحالية إلى التعرف على المتغيرات الإجتماعية والنفسيه المرتبطه بعمليات

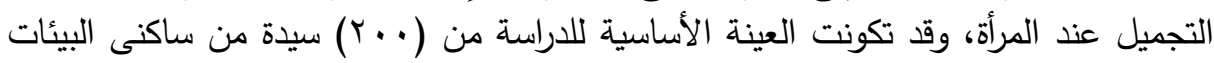

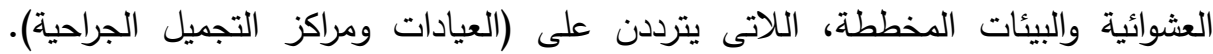

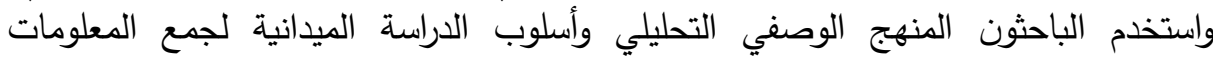
والبيانات اللازمة لإتمام الدراسة. بالإعتماد علي الأدوات "الإستبانة، مقياس الإنيات المتغيرات النيات النفسية، مقياس المتغيرات الإجتماعية).

ولقد توصلت الدراسة إلى بعض النتائج من اهمها وجود علاقه ارتباطية عكسية بين اتِّجَاه

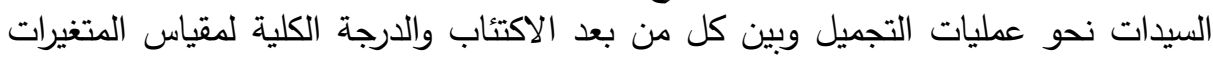

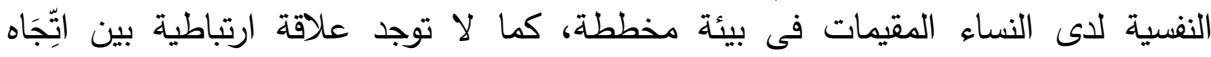
السيدات نحو عمليات التجميل والمتغير لدى النساء المقيمات فى بيئة عشوائية وبين كل من النية لإنة

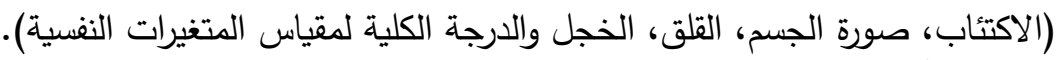

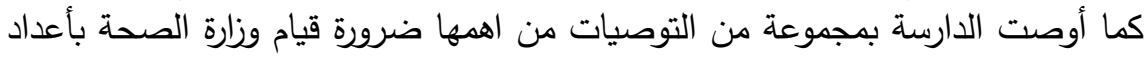

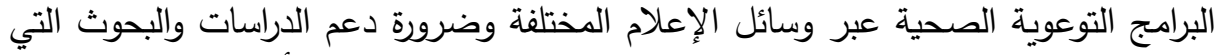

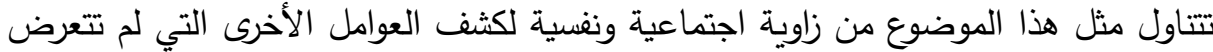

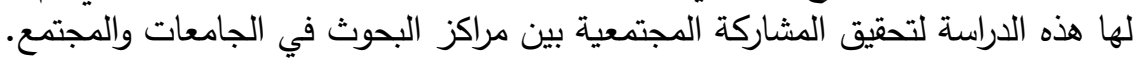




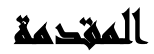

ان شيوع عمليات التجميل في ازدياد بمعدلات مفزعة عالميا سواء في الدول المتحضرة او النامية ؛لذا تعتبر عمليات التجميل من الموضوعات الصحية النفسية والاجتماعية البالغة الخطورة والأهمية في حياة الفرد والمجتمع، ومما يزيد من خطورتها هو استهدافها لصورة الصنيك الجسم التي تؤثر علي نمو الثخصية وتطورها، فما يكونه الفرد من اتجاهات نحو جسمه قد في

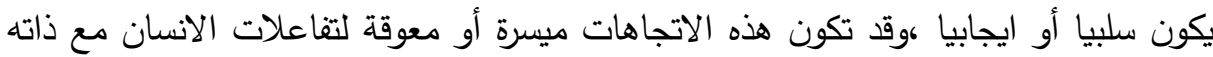
ومع الاخرين ،كما تتضمن صورة الجسم أدراكا لثكل الجسم وحجمه ولذا في كثيرا من الأحيان يكون المفهوم السالب للذات راجعا الي تثوه صورة الجسم، وهذا ما نجده واضحا لدي الافراد المصابين بالسمنه وعلي العكس من ذلك يصاحب المفهوم الايجابي لصورة الجمم شعور

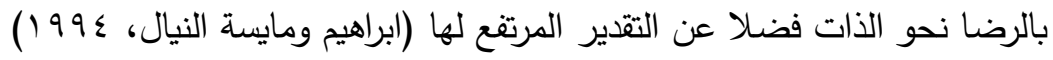
تشكل عمليات التجميل خطورة كبيرة علي الجسم تتمثل في حدوث تثوهات بالإضافة إلي لئي

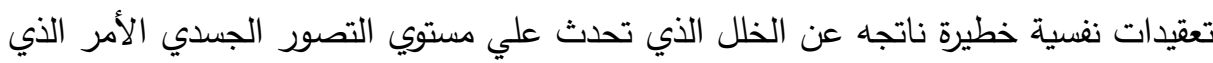
يؤثر حتما وبصفة مباشرة علي الجانب النفسي حيث أن كل فرد يحمل صورة عقلية مثالية

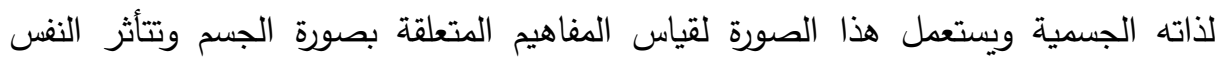
الأجتماعية بعدة عوامل كالقلق، الأكتئاب، الخجل. الا ان الجسم معرض لعدة اضطرابات كالحوادث والأمراض التي من شأنها تثوه صورته لإنه

الجمالية وتفقده جاذبيتة كالإصابة بمرض العصر "السمنة" (Puzziferr N, 2005) ولقد انتشرت عمليات التجميل بين الجنسين فى الآونة الأخيرة بصورة كثيفة فى العالم العربى بصفة عامة وفي مصر بصفة خاصة حيث شهدت عيادات ومراكز التجميل إقبالاً متزايداً من النساء والرجال ومن مختلف الفئات العمرية لإجراء جراحات التجميل. ويرجع انتثار عمليات التجميل إلى زيادة الوعي والثقافة الخاصة بهذه العمليات والتركيز الإعلامى المتتامى بموضوعات التجميل كما أن وسائل الإعلام المختلفة المسموعة والمرئية 
والمقروهة والإنترنت وخاصة القنوات الفضائية التى خصصت برامج خاصة بموضوعات الجمال وجراحة التجميل ساهمت بثكل مباشر فى زيادة الإقبال على إجراء مثل هذه العمليات.

كما أن العصر الذي نعيشه يوصف بأنه "عصر الصورة" حيث أصبحت الصورة تلعب

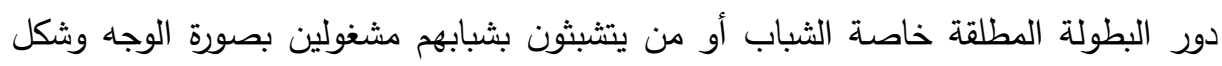

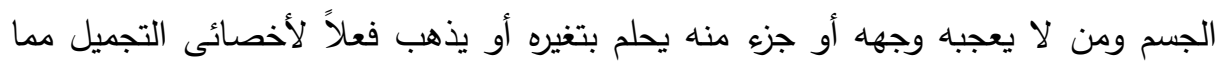

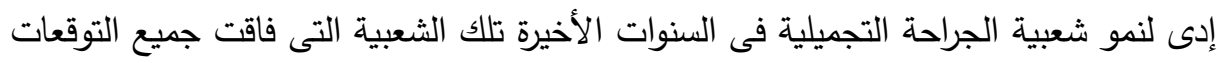

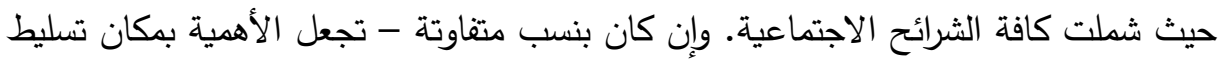

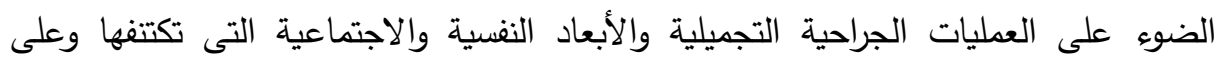

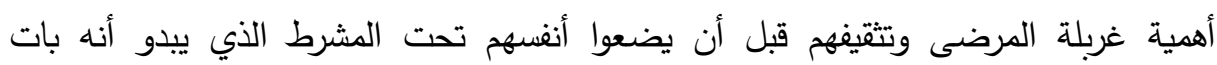
الصولجان السحري للحياة المعاصرة والمجتمع الاستهلاكي الذي نعيش فيه. وعلى الرغم من أن فن التجميل بدأ منذ عصر الفراعنه بزراعة الجلد، وظهر اهتمام الهنود الهيته بزراعة الجلد، أو نقل قطع منه من مكان إلى أخر في الجسم. كما ان هناك شواهد على منى معرفة العرب لهذا النوع من الجراحه واليوم صارت نازلة التجميل من المسائل الثائعه في الحياة

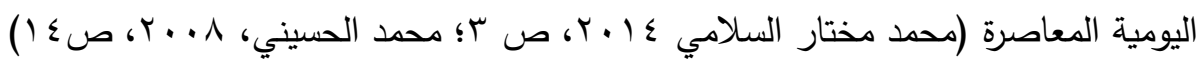
وتحرص المرأة علي ان تتمتع بصوره جسمية جذابة ومقبولة وذلك وفقا للصوره التي

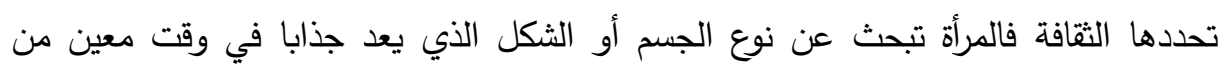

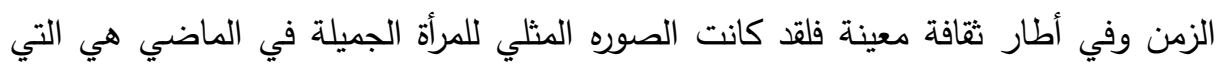

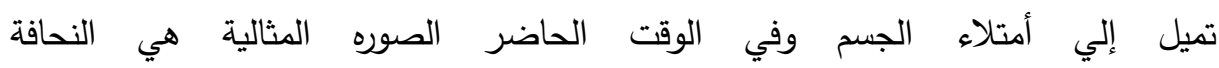

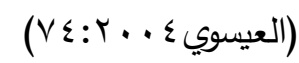

ويري سيمون دي بوفوار أن فقدان الثقة في الجسم يؤدي إلي فقدان الثقة في النفس حيث

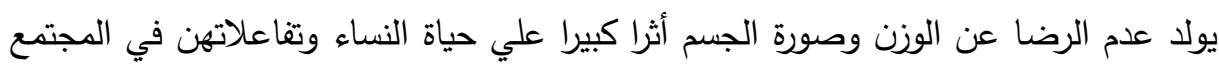

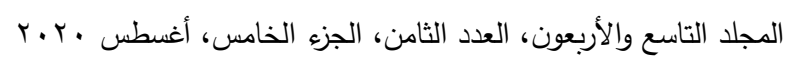

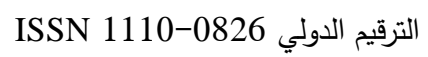


،حيث تتضمن صوره الجسم الاهتمامات المنغرسة في خبرات النساء بوزن وشكل أجسامهن ،ويشمل هذا ادراكاتهن لتأثير الرسائل المجتمعية بخصوص النمات النحافة في حياتهن ،فالنساء تتلقين رسائل لا تتتهي عن صورة اجسامهن من مصادر قريبة مثل الوالدين ،والأصدقاء والإخوة وزملاء العمل، أو مصادر أكثر شمولا كالإعلانات في المجلات والتلفزيون، وصناعة الأنياء الذي غيرت كثيرا في مفهوم المرأة لصوره جسمها حيث أصبحت النساء تسعي للوصول الإعان فئ للنحافة كمثال لجمال الجسم. ففي دراسة لثيمبسون (Thompson J., 1995) وجد أن المضايقات التي تتعرض لها الفتاه من الأسرة والأقران بسبب وزنها تسهم في وجود رؤية سلبية لديها عن جسمها.

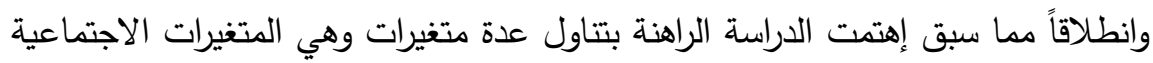
والنفسية وعلاقتها بعمليات التجميل عند المرأة.

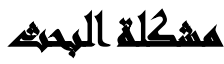

ان الادراك الخاطئ للصوره التي تبدو عليها اجسادنا قد تظهر اثار ضارة،لا سيما عدم

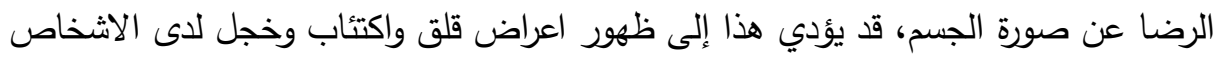

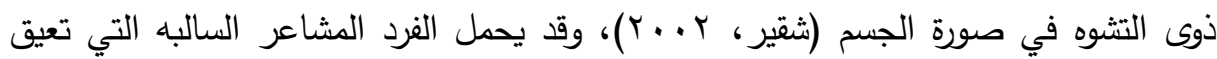
وصوله للتوافق النفسي السوي، ما يؤدي إلى الكثير من الامراض النفسيه؛ كاضطراب الوسواس القهري ،اضطراب تشوه الجسد، واضطرابات القلق بوجه عام، والقلق الاجتماعي بوجه خاص؛ لان الافراد يبنون صوره اجسادهم وذاواتهم من خلال تفاعلهم في البيئه التي يعيشون فيها ،اذا انها المرأة العاكسه التي يخزنون من خلالها مدركاتهم وتصورتهم عن صوره اجسامهم ومفهومهم لذواتهم .فهناك اعتقاد سائد بين الناس بأهميه عمليات التجميل التي قد دادئ تزيد من تقبل الفرد لصورة جسده فتزيد من امكانيته لتقبله ذاتة، وتزيد من تقبل المجتمع له. فتتامي اهتمام الاشخاص باللجوء إلى اجراء عمليات التجميل سعيا وراء الحصول على الثكل 246

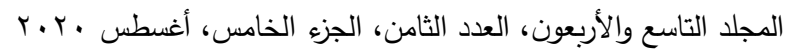

$$
\begin{aligned}
& \text { الترقيم الدولي 0826-0 1110 }
\end{aligned}
$$


المقبول والمطلوب، وفي أرجاء منطقة الثرق الأوسط، زادت عمليات شفط الدهون والحقن

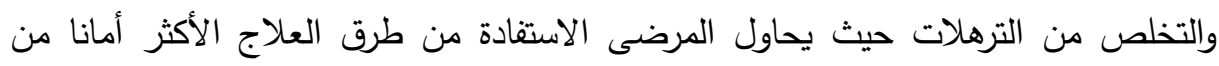
خلال التقدم التكنولوجي المتنامي.

وتحتل مصر ترتيبا عالميا متقدما في عمليات التجميل واستتدت الصحيفة على لئى إحصائيات نشرتها "الجمعية العالمية لجراحي العمليات التجميلية"، كثفت أن مصر بئيات بين أعلى

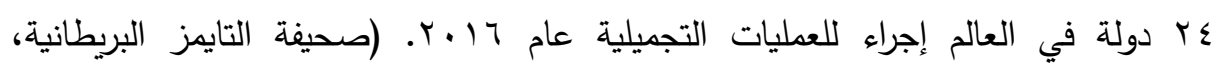

الإطلالة الجميلة مطلب لكل انثى لدرجة عدم الاقتتاع - احياناً - بالجمال الموجود أصلاً وعليه فأن ثقافة التجميل أصبحت أكثر انتثاراً كونها أبرز الإختبارات التى تلجأ إليها

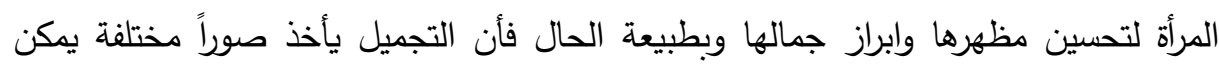
حصرها فى محورين أساسيين هما:

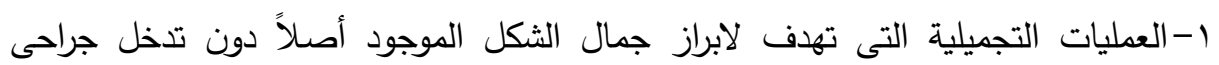

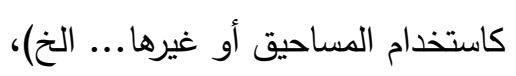

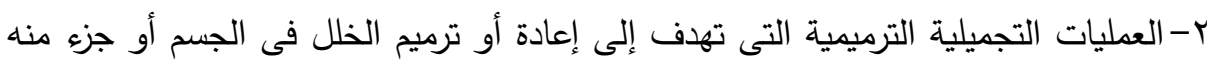
من خلال التذخل الجراحى كعمليات شد البطن أو تصغير الانف أو تكبير الثذيين.... الخ.

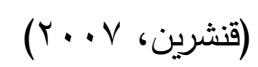

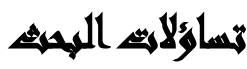

سعت الدراسة الحالية للإجابة على تساؤل رئيسى: هل توجد علاقة بين المتغيرات الاجتماعية والنفسية والديموجرافية واقبال المرأة على تلى

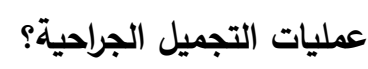
ويندرج من هذا التساؤل عدد من التساؤلات الفرعية أهمها:

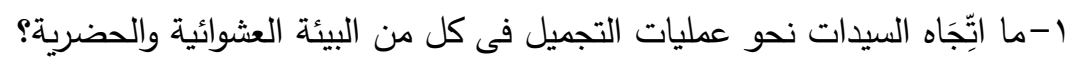

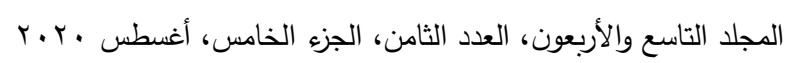


ץ- هل توجد علاقة بين اتجاه المرأة نحو عمليات التجميل وبعض المتغيرات النفسية وتشمل

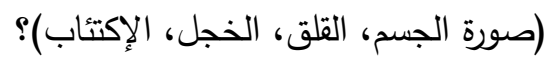
r-هل توجد علاقة بين اتجاه المرأة نحو عمليات التجميل وبعض المتغيرات الأجتماعية

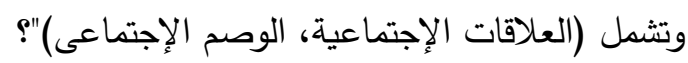

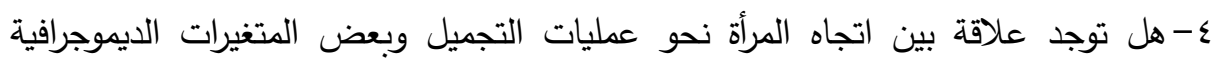
وتثمل (العمر - الحالة الاجتماعية - الحالة المهنية - الدخل الثهرى - مكان السكن)

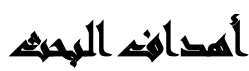

تتمثل أهداف الدراسة فى هدف رئيسى واحد وهو: "معرفة العوامل الإجتماعية والنفسية المرتبطة فى إقبال المرأة على عمليات التجميل الجراحية: وينقسم إلى مجموعة من الأهداف الفرعية وتثمل: الفئل 1- التعرف على اتجاه المرأة نحو عمليات التجميل في كل من البيئة العشوائية والحضرية.

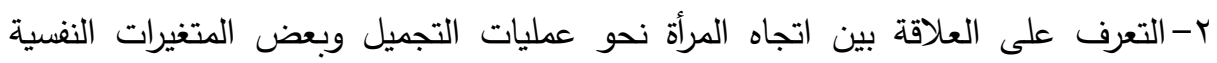
وتثمل (صورة الجسم، القلق، الخجل، الأكتئاب).

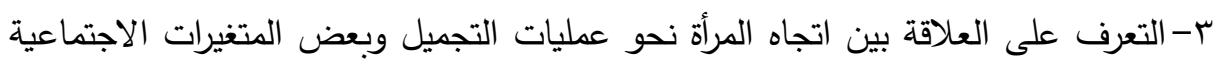
وتثمل (العلاقات الاجتماعية، الوصم الاجتماعي).

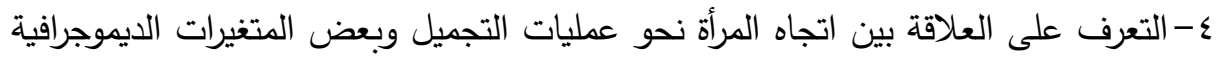
وتشمل (العمر - الحالة الاجتماعية - الحالة المهنية - الدخل الثهرى - مكان السكن). ه-الكثف عن الفروق بين استجابات أفراد عينة الدراسة على المتغيرات النفسية تبعًا لمتغير الفئه مكان السكن (البيئة العشوائية والمخططة).

צ-الكثف عن الفروق بين استجابات أفراد عينة الدراسة على المتغيرات الإجتماعية تبعًا لمتغير مكان السكن (البيئية العشوائية والمخططة). 


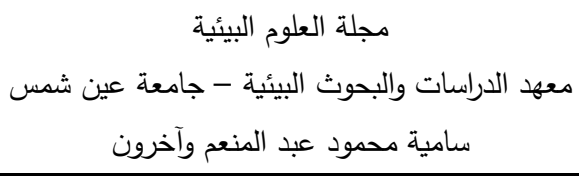

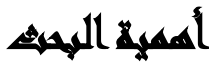

تتمثل أهية الدراسة فى النقاط التالية:

الأهمية النظرية: لفت نظر المؤسسات والجمعيات ومراكز البحوث العلمية والأجتماعية وغيرها لإجراء المزيد من الدراسات والبحوث حول هذا الموضوع بغرض الوصول إلى نتائج علمية منطقية تساعد فى التعرف على الأسباب والظروف المرتبطة فى الأقبال على عمليات التجميل الجراحية رغم ما يكتنفها من مخاطر قد تؤدى إلى الوفاة فى حال فثلها.

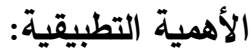
• أن دراسة هذا الموضوع تثكل أهمية تطبيقية كبيرة يأتى من بينها ما سوف تسفر عنه نتائجها وتوصياتها من إفساح المجال أمام المخططين والمهتمين والمسئولين فى التوعية

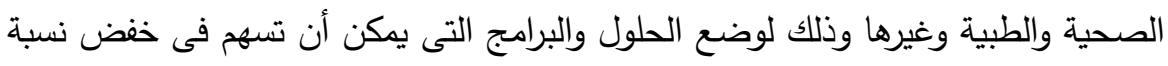

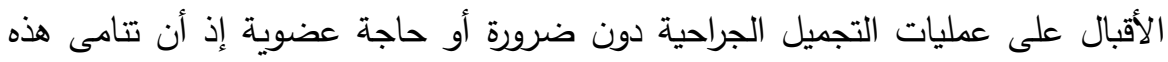
الظاهرة وتفشيها بالمجتمع سوف ينعكس سلبياً على صحة الأنسان بشكل عام.

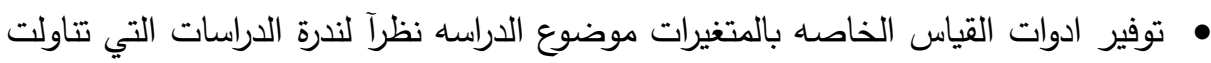
العلاقة بين عمليات التجميل وبعض المتغيرات الإجتماعية والنفسية.

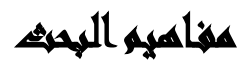

عرفت العمليات التجميلية بأنها: "مجموعة العمليات التي تتعلق بالثكل والتي يكون الغرض منها علاج عيوب طبيعية أو مكتسبة في ظاهر الجسم البشري". (علي المحمدي

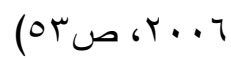

مفهوم المتغيرات النفسية: "هي تلك العوامل التي تؤثر علي المرأة وتجعلها تلجأ الي عمليات التجميل سواء بهدف إجراء العمليات الجراحية لعلاج أي مثكلة خلقية أو لـعالجة السمنة أو أو نتيجة لأي حادث تعرضت له أو كانت بغرض التجميل مثل إجراء عمليات بهدف الحصول

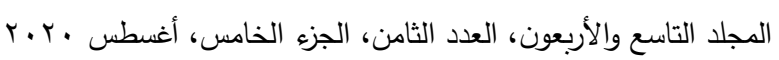

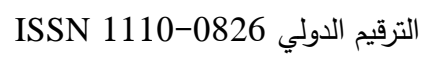


علي هيئة معينة مرغوبة إجتماعيًا، وهى تمثل الدرجة التى تحصل عليها السيدات على مقياس

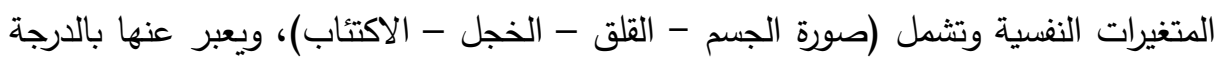
التي تحصل عليها المبحوثات علي مقياس المتغيرات النفسية بأبعاده المحددة".

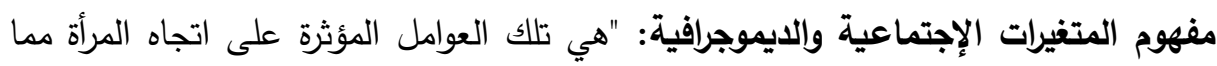

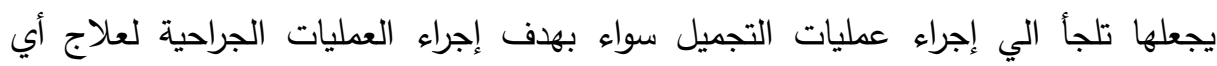
مشكلة خلقية أو لمعالجة السمنة أو نتيجه لأي حادث تعرضت له له أو كانت بغرض التهاء التجميل

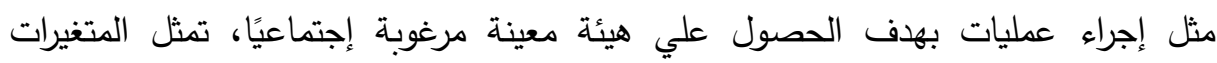
الإجتماعية الدرجة التى تحصل عليها السيدات على مقياس المتغيرات الإجتماعية وتثثل هلئه (العلاقات الإجتماعية - الوصم الإجتماعى)، بينما تثمل اللمتغيراتت الديموجرافية (العمر الحالة الإجتماعية - المؤهل العلىى - الحالة المهنية - الدخل الثهرى) ويعبر عنها بالدرجها التي تحصل عليها المبحوثات علي مقاييس المتغيرات الإجتماعية والديموجرافية بأبعاده

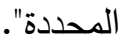

\section{الدواسواهث الماوهية}

أولًا: دراسات تناولت اتجاه المرأة نحو عمليات التجميل:

دراسة (هيثم جمجوم ستوب، 1 . . ץ) بعنوان: "عمليات التجميل في السعوديه". هدفت الى أغرض صحيه وطبيه حيث اشارت إلى ارتفاع حجم الاقبال السيدات في الاونه الاخيره على لهئ عمليات التجميل حيث بلغت (•9\%) بحيث لا تتعدى نسبه اقبال الرجال على عمليات

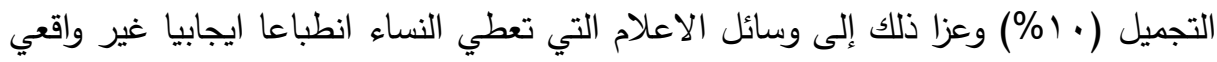
لنتائج عمليات التجميل لاسيما وأنهن اكثر اهتماما بمظهرهن الخارجي من الرجال وكذلك إلى الى الى التيطي

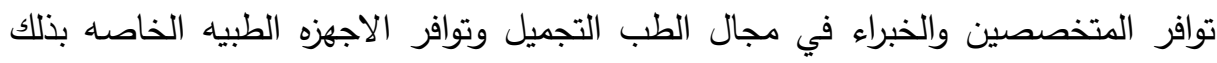
وتقدم مجال الطب في السعوديه ما ادى إلى عدم الاحتياج للسفر خارج البلاد اذا ساهم ذلك 250

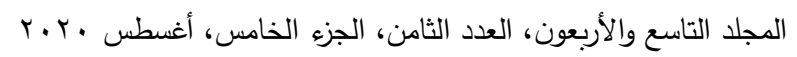
الترقيم الدولي 0826- ISSN 1110 
بأنفاض تكاليفها الامر الذي جعل عمليات التجميل لا تقتصر على شريحه معينه من المجتمع كما بينت الدراسه أن اكثر عمليات التجميل الجراحيه اقبالا من الديدات هي شفط التطيل الدهون وشد البطن ورفع الصدر او تصغيره وان اكثر العلاجات غير الجراحيه انتثارا بين السيدات هي: حقن البوتوكس ونفخ الثفتين والوجنتين بينما اكثر عمليات التجميل الجراحيه

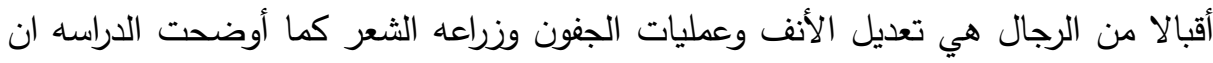

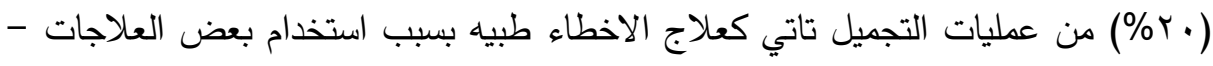
مثل حقن البوتوكس من قبل العاملات غير المتخصصات في صالونات التجميل او الاطباء الذين يفتقرون للخبره الكافيه ما يترتب عليه وجود مضاعفات جانبيه خطيره أقلها الاصابه بشلل نصفي في الوجه.

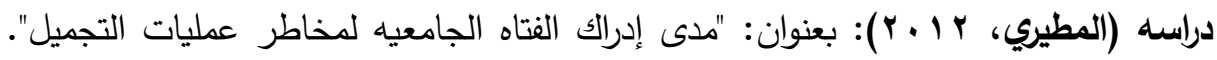
هدفت الدراسه الى الكشف عن العوامل المؤثره في لجوء الفتاه الجامعيه لعمليات التجميل والكثف عن انواع عمليات التجميل الاكثر انتشارا بين الفتيات الجامعيات والكثف عن لهن مصادر الحصول على المعلومه في اجراء عمليات التجميل والكشف عن مدى اسهام بعض العض التصات

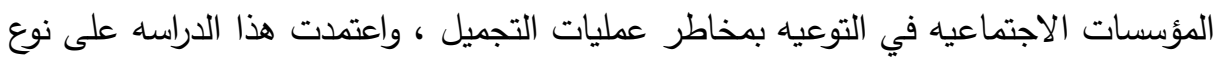

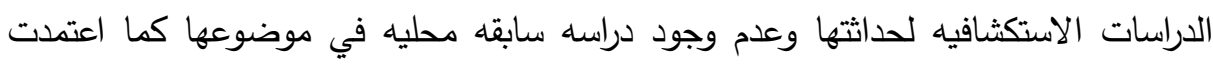
علي منهج المسح الأجتماعي بالعينه وقد تمثلت عينه الدراسه من طالبات جامعه الدمام درام

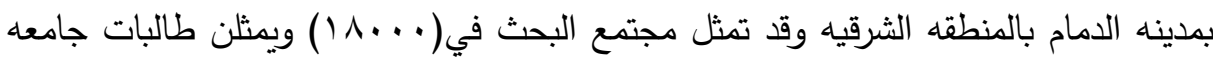

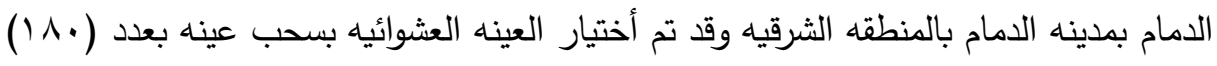

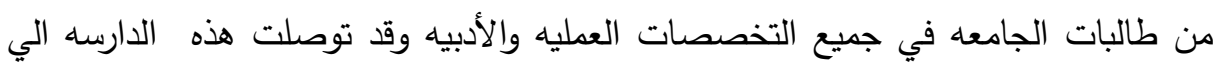
عدد من النتائج من أهمها، ارتفاع أستجابه افراد العينه على محور مدى ادراك الفتاه لمخاطر

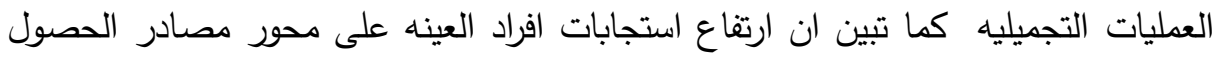

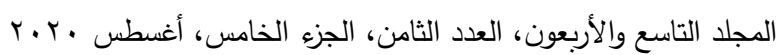

$$
\begin{aligned}
& \text { الترقيم الدولي 0826-0 1110 }
\end{aligned}
$$


على المعلومه لإجراء عمليات التجميل وكذلك تبين ارتفاع متوسط استجابات افراد العينه على إسهام بعض المؤسسات الاجتماعيه في توعيه الفتيات بمخاطر عمليات التجميل.

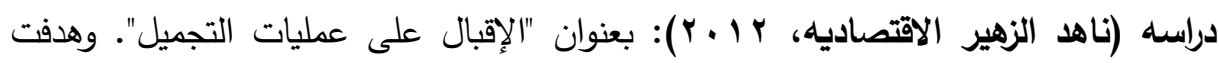

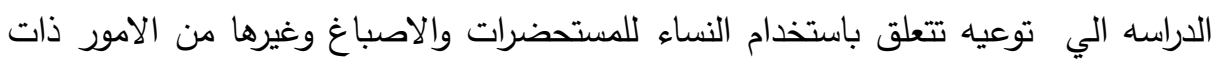
العلاقه بالتجميل وأظهرت نتائج هذه الدراسه ان اكثر الفئات العمريه اقبالا على عمليات

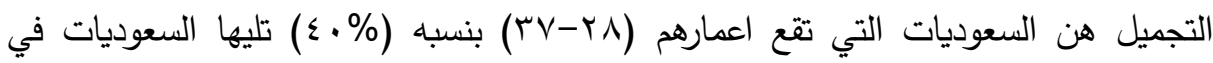

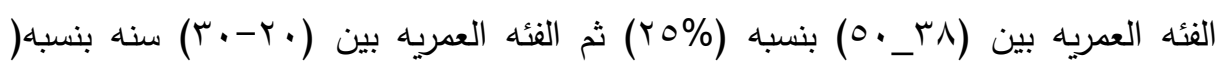

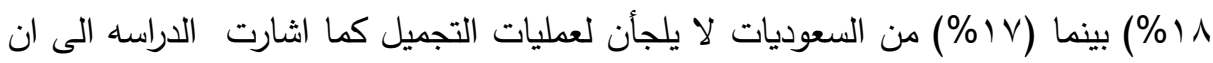
(\%rv) لعمليات التجميل مستقبلا وان (•9\%) من السعوديات غير راضيات عن مظهرهن وجمالهن

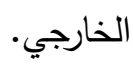

ثانياً: دراسات تناولت عمليات التجميل لاى المرأة وعلاقتها ببعض المتغيرات الإجتماعية والنفسية: دراسة (القاضي، 1 . . ץ): بعنوان: "قلق المستقبل وعلاقته بصوره الجسم ومفهوم الذات لإى حالات البتر بعد الحرب على غزه". هدفت إلى التعرف على قلق المستقبل وعلاقته بصوره

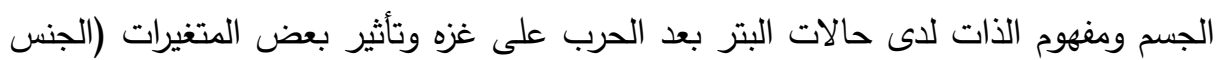

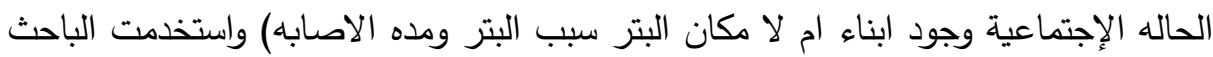

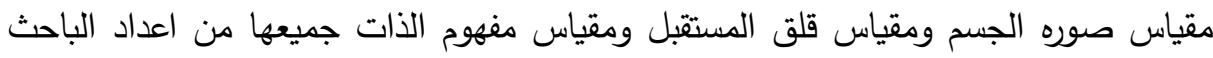
على عينه قوامها (.0. Tردا) من حالات البتر واستخدمت الباحثة في معالجه الاحصائيه عدد من المقاييس وهي التكرارات والنسب المئويه اختبار t-test وتحليل التباين والمتوسطات

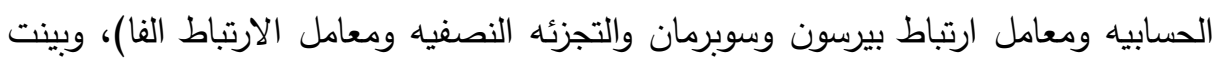

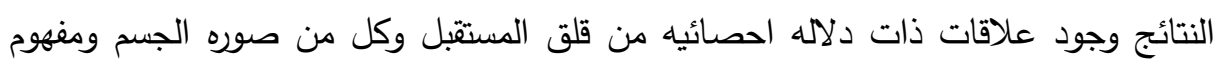
252

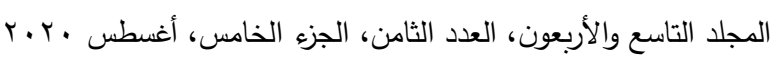

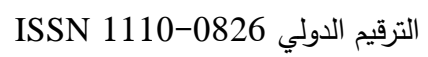


الذات لاى حالات البتر في قطاع غزه كما انه لا توجد علاقه دالة احصائيا في صوره الجسم تعزي للجنس او الحالة اجتماعيه .

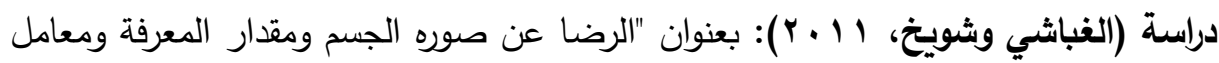
كتله الجسم ونوع وموطن الإقامة كمتنبئات بسلوك الاكل المرتبط بالصحه لإنى لدون طلاب

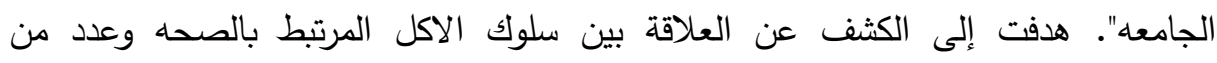
المتغيرات هي الرضا عن الجسم ومعامل كتله الجسم والنوع وموطن الإقامة اجريت هذه بهن

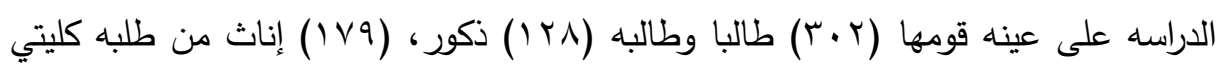

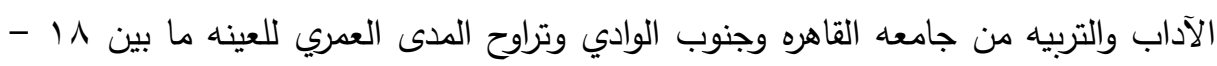

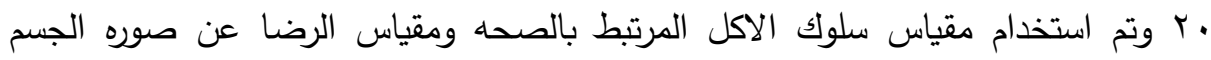

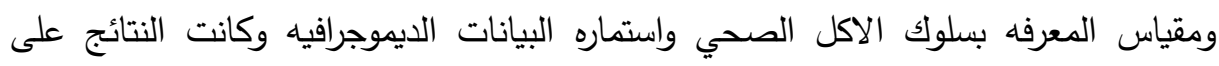

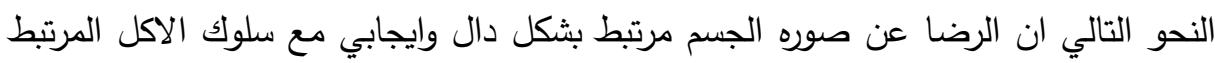

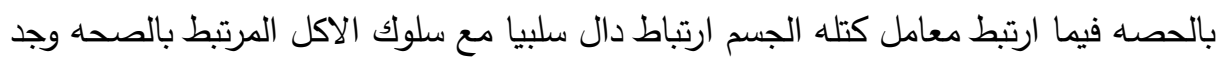
تأثير دال لكل من الرضا عن صوره الجسم ومعامل كتله الجسم والنوع على السلوك الاكل

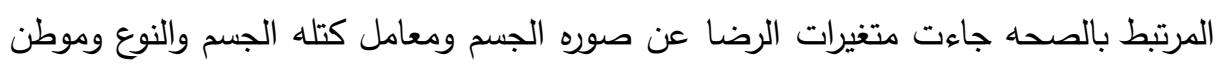
الاقامه قادر على التتبؤ بسلوك الأكل المرتبط بالصحة لدي طلبه الجامعاءه بمستوى دلاله عالي

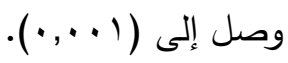
دراسه (Lobera, 2011): بعنوان "صوره الجسم ونوعيه الحياة لدي سكان اسبانيا". فكان

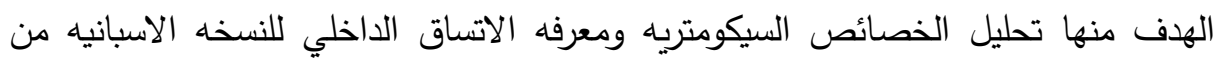
صوره الجسم ونوعيه الحياة للي سكان اسبانيا فضلا عن موثوقيه اعاده اختبار تجربتها كما هدفت لتحليل العلاقات المختلفة مع الابعاد الاساسيه للاداء النفسي والاجتماعي وهي (احترام

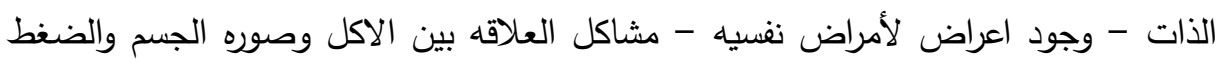
والاجهاد) ومعرفه ما إذا كان هناك اختلافات في صوره الجسم ونوعيه الحياة تعزي لكتغير

$$
\begin{aligned}
& \text { المجلد التاسع والأربعون، العدد الثامن، الجزء الخامس، أغسطس . r.r. }
\end{aligned}
$$

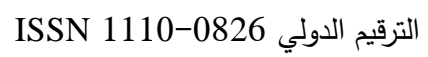


الجنس. تالفت عينه البحث من (IVV) طالب وطالبه من جامعتي بابلودي أوليفد وجامعه

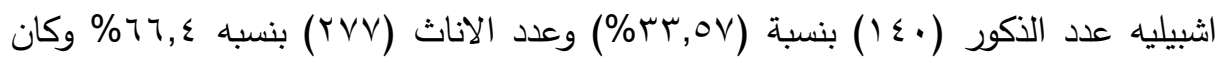

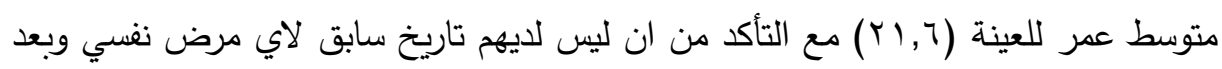
موافقه جميع المشاركين تم استخدام المقاييس التاليه (مقياس اضطراب لإن الاكل، استبانة

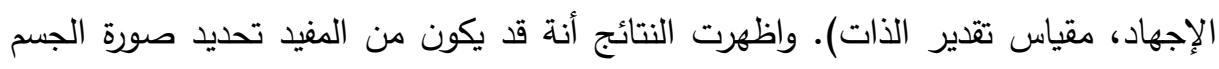
حسب نوعية الحياة في ظروف فيزيائيه مختلفة كما ارتبطت صورة الجسم الايجابية باحترام أكبر للذات وراحة نفسيه أكبر وعدد اقل من مرات الاختلال في الاكل هذا وكانت هذه النتائج أكثر وضوحا لاي الاناث منها لدي الذكور .

\section{الإسار النظظيه}

اصبح البشر خاصه الثباب او من يتشبثون بالمحافظه على شبابهم، مشغولين بصورة

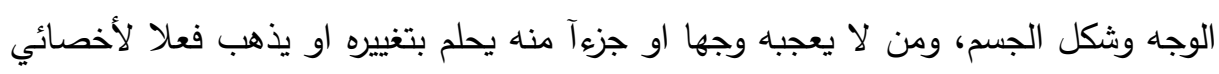

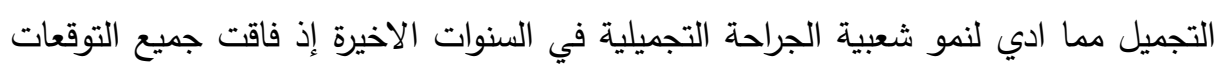
والتي شملت كافة الشرائح الاجتماعيه، وان كانت بنسب متفاوته (معاويه 9 . . ب). النظريات التي فسرت صورة الجسم: هناك عدد من النظريات التي فسرت أسباب ظهور صورة الجسم، وهي كالآتي:

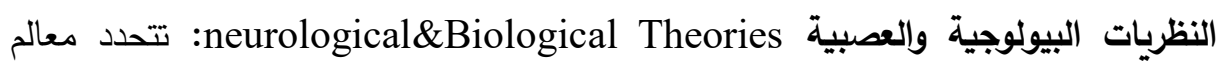
الجسم بثكل كبير بالعوامل البيولوجية والوراثية، والتي قد تئدي بـه الخصائص البيولوجية

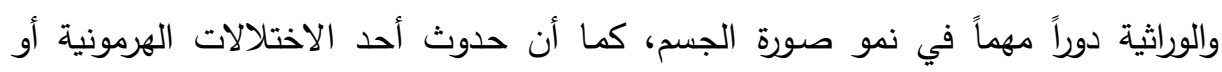

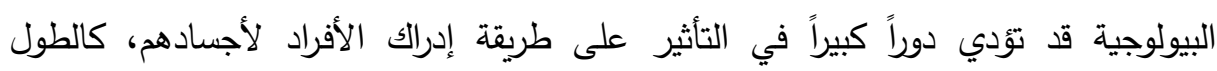

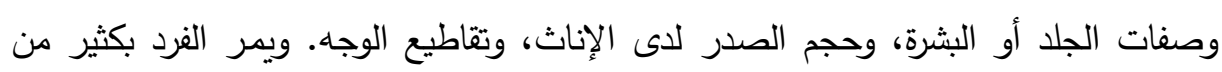


التغيرات البيولوجية في أثثاء نموه، فتتزايد لديه مشاعر الارتباك والرهبة، التي من شأنها التأثير في كيفية إدراك الثخص لجسده (Strickland,2004)

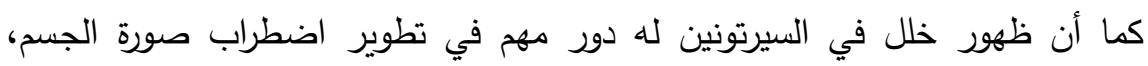

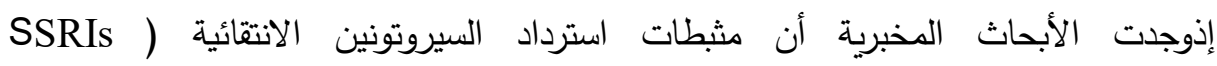
(Medications (Hadley ,Newcorn (Hollander,2002)

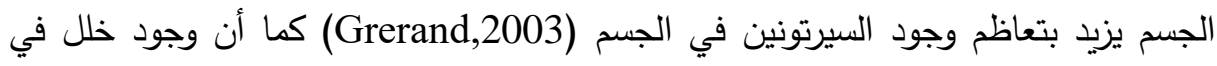
مادة الدوبامين في الجسم، قد تشكل عاملاً مؤهباً لتطوير اضطراب لبعاب صورة الجسم. هذا وبينت

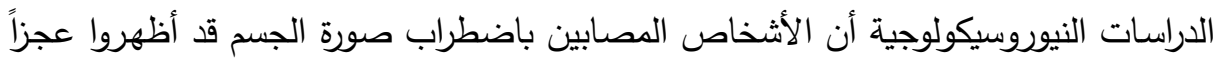
في قدرات التذكر والترميز (Deckers bach, et al, 2000) الذي بدوره يظهر وجود خلل في العقدة المخططه Striatal-Frontal والنظام الدوباميني Dopaminergic system. ., 2002) et al Hadley( النظريات المعرفية السلوكية: تؤمن النظريات المعرفية السلوكية بأن ظهور اضطراب صورة

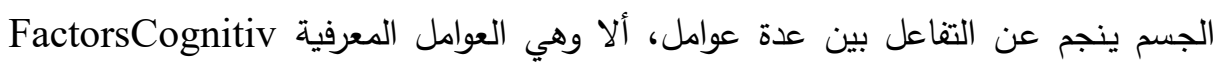
والعوامل الانفعالية (Factors Emotional) والعوامل السلوكية (Factors Behaviora) والعوامل الثقافية الاجتماعية وتَرد النظريات المعرفية السلوكية ظهور اضطراب صورة الجسم إلى مرحلة المرأة، والتي تُعد من أهم المراحل النمائية التي يهتم بتردية بهات الأفراد بما يبدو عليه

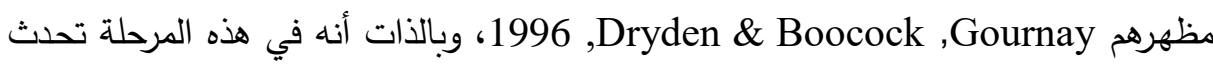
التغيرات الجسمية وتصبح ملاحظة من قبل الآخرين، ما يحدو بالثخص أن يركز انتباهه

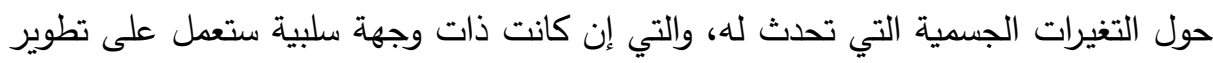


Orosan \& Reiter, ,1995) معتدات خاطئة عند الثخص حول ما ييدو عليه شكله

(Rosen

كما أن حدوث تشوهات في المنظومة المعرفية لاى الشخص من شأنها أن تطور اتجاهات غير واقعية عن صورة الثخص حول جسده، والتي تهدف إلى الوصول إلى الكمال والتتاسق التّام في الجسم، وهو بالتأكيد مطلب صعب صون المنال. (Boocock \&Veale,Gournay,Dryden, 1996)

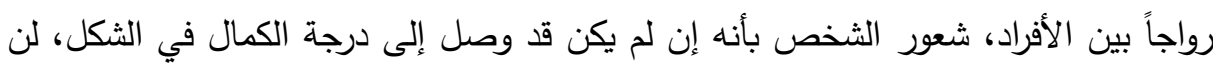

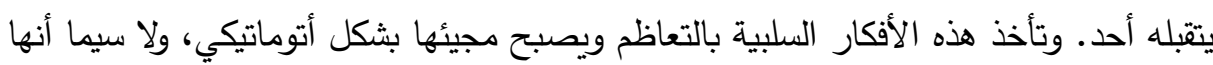

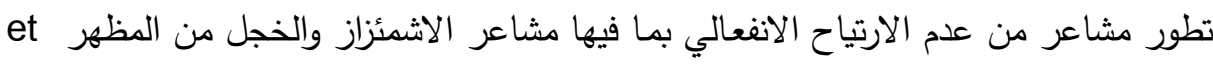

(Rosen et al ; 1995, 96 ;Vealeal ,1996,55)

كما أن عوامل معرفية أخرى كالانتباه الانتقائي لعيب مدرك في الجسم، وتعاظم ملاحظة

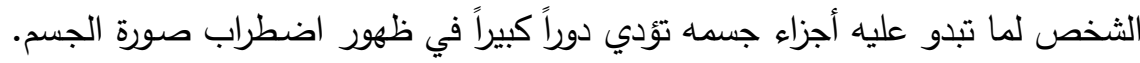
(Veale,et al.,1996, 56) كما أن الأشخاص المصابين باضطراب صورة الجسم ينخرطون في القيام بتكرار طقوس

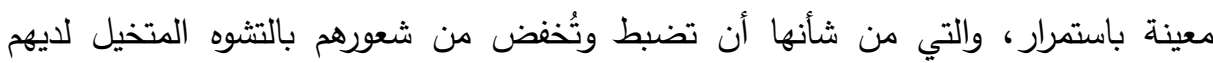
أجسادهم. ., 1996)Veale et al(

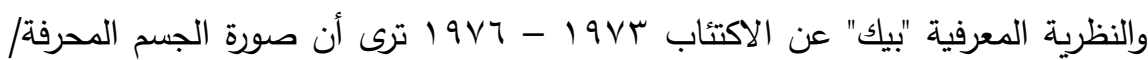
المشوهة تكون عرضاً معرفياً للاكتئاب. (A ,Moitra) النظريات النمائية والاجتماعية الثقافية لصورة الجسم: النظريات النمائية والاجتماعية والثقافية تفسر وتشرح كيف أن صورة الجسم تتمو وتتطور؟ وأن فهم تلك

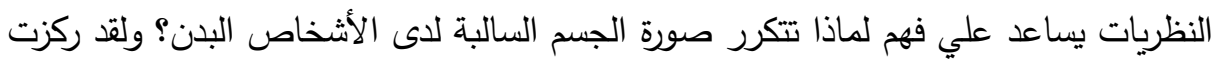


النظريات النمائية على أهمية مرحلة الطفولة والمرأة كفترة هامة، وفي أثنائها تتمو وتتطور صورة الجسم، وأن هناك عوامل مثل:" وقت البلوغ " الذي يسهم في نمو صورة الجسم، وتهدف النظريات الثقافية والاجتماعية إلى عقد المقارنة الاجتماعية والوسائل الثقافية الاجتماعية، بخصوص الهيئة والمظهر الخارجي والجمال كعوامل هامة في نمو وتطور صورة الجسم الإعي

.(Reas, 2002:6)

\section{الإجراعائ المنهجية اللهشيه}

منهج الدراسة: اعتمد الباحثون في هذه الدراسة" المنهج الوصفي التحليلي " وأسلوب الدراسة الميدانية لجمع المعلومات والبيانات اللازمة لإتمام الدراسة. عينة الاراسة: وقد تألفت عينة الدراسة من: 1. العينة الإستطلاعية: أجريت هذه الدراسة الاستطلاعية على عينة مكونة من (•ع) سيدة

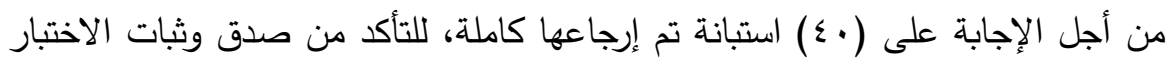

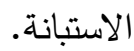

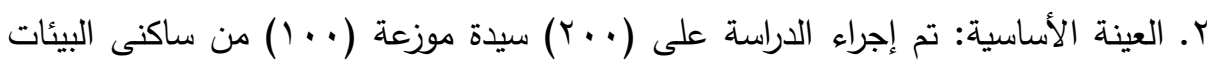

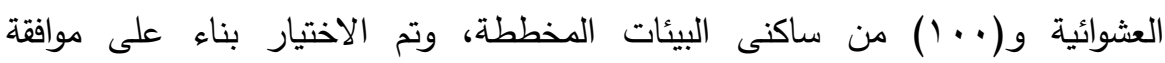

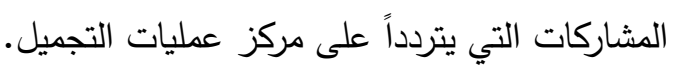

أدوات الاراسة: نظراً لطبيعة الدراسة الحالية فقد تم اختيار الاستبيان كأداة رئيسية لجمع البيانات من المبحوثين وذلك عن طريق الاتصال المباشر الثخصي المتعد القائم على التفاعل وجهاً لوجه بين الباحث والمبحوث. تصميم أدوات الاراسة: أعتمدنا في الدراسة الحالية على الأدوات التالية: ا ـ استبانة اتجاه المرأة نحو عمليات التجميل: تتكون هذه الاستبانة مما يلي:

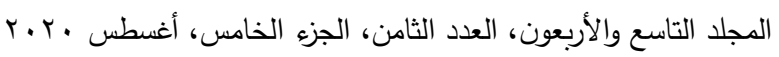


الجزء الأول: يتضمن البيانات الثخصية.

الجزء الثاني: يتضمن بعدين لمعرفة تجاه المرأة نحو عمليات التجميل ومدى اقبالها عليها، أما

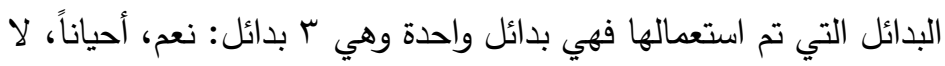
r. مقياس المتغيرات النفسية ويشمل الابعاد (صورة الجسم، القلق، الاكتئاب، الخجل). r. مقياس المتغيرات الاجتماعية ويشمل الابعاد (الوصم الاجتماعي - العلاقات الاجتماعية).

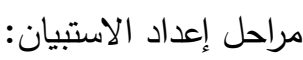
- مرحلة الصياغة المبدئية: تم تحديد الصياغة المبدئية لأستمارة الاستبيان بناءاً على الألى الأهداف والتساؤلات الخاصة في هذه المرحلة.

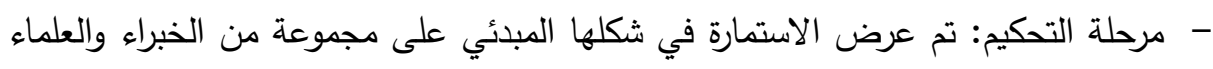
المتخصصين في مجالي علم الاجتماع والنفس لتحكيم الاستمارة.

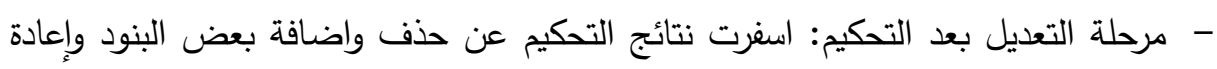
صياغة البعض الاخر بناءاً على توصيات السادة المحكمين وتم إعادة صياغة استمارة الاستبيان في شكلها الجديد بعد التحكيم.

للتأكد من أداة الدراسة المستخدمة تستطيع أن تقيس ما وضعت من أجله من خلال الصدق والثبات وسنتطرق إلى كيفية حساب كل خاصية من هاتين الخاصيتين. 


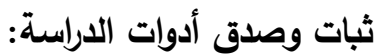

جدول (1): ثبات وصدق الاتساق الداخلى استبيان اتجاه المرأة نحو عمليات التجميل

\begin{tabular}{|c|c|c|c|c|c|}
\hline معامل ارتباط & العبارة & $\begin{array}{c}\text { معامل ارتباط بيرسون } \\
\end{array}$ & العبارة & قيمة & أبعاد المقياس \\
\hline$\because, 179$ & V & $" *, \wedge \wedge 9$ & 1 & \multirow{6}{*}{., 09.} & \multirow{6}{*}{ الدرجة الكلية لاستبيان اتجاه المرأة } \\
\hline., 179 & $\wedge$ & $" *, \wedge \ldots$ & $r$ & & \\
\hline$\because, 101$ & 9 & $" *, Y Y I$ & $r$ & & \\
\hline$\because, 171$ & 1. & $" *, Y Y I$ & $\varepsilon$ & & \\
\hline \multirow[t]{2}{*}{$\because, 100$} & 11 & $" \cdot, r V$. & 0 & & \\
\hline & & $\because, 179$ & 7 & & \\
\hline
\end{tabular}

تبين من ثبات الاستبيان من خلال معادلة ألفا كرونباخ (Alpha Cronbach)، ثبات

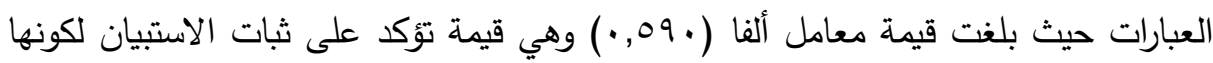

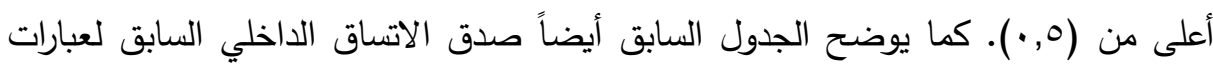

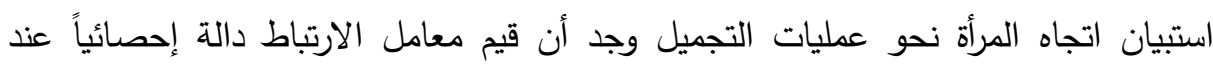
مستوى معنوية (0.. •)، مما يؤكد على صدق الاتساق الداخلي لعبارات استبيان اتجاه المرأة نحو عمليات التجميل. جدول (ץ): ثبات وصدق الاتساق الداخلى لمقياس المتغيرات النفسية

\begin{tabular}{|c|c|c|c|}
\hline الدلالة المعنوية & معامل ارتباط بيرسون & قيمة ألفا & أبعاد المقياس \\
\hline.,$\ldots$, & •, ᄉ & $\cdot, \wedge \cdot q$ & صورة الجسم \\
\hline$\cdot, \ldots 1$ & $\cdot, 9 \cdot 9$ & $\cdot, \wedge \wedge 7$ & 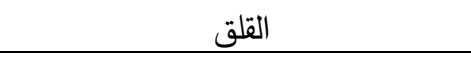 \\
\hline$\cdot, \cdot r$ & $\cdot, 179$ & $\cdot, 0 \leqslant 1$ & الخجل \\
\hline.,$\ldots$, & •, AץA & $\cdot, \vee \vee 90$ & الاكتئاب \\
\hline & & $\cdot, \wedge \wedge 9$ & الدرجة الكلية لمقياس المتغيرات النفسية \\
\hline
\end{tabular}

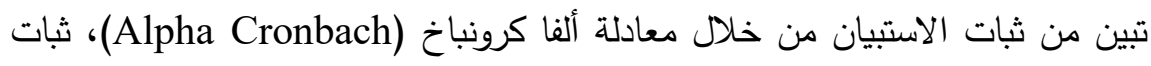

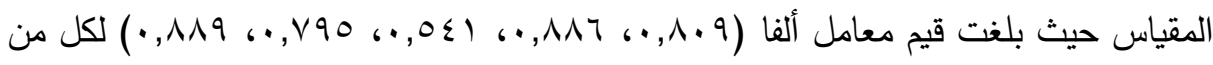

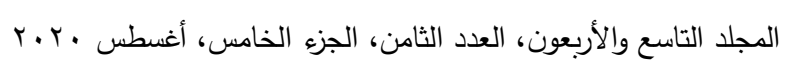

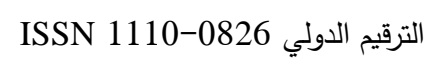


(صورة الجس، القلق، الخجل، الاكتئاب، الدرجة الكلية لمقياس المتغيرات النفسية) على

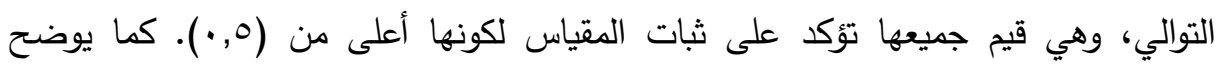
الجدول السابق أيضاً الاتساق الداخلي للمقياس وجد أن قيم معامل الارتباط دالة إحصائياً عند

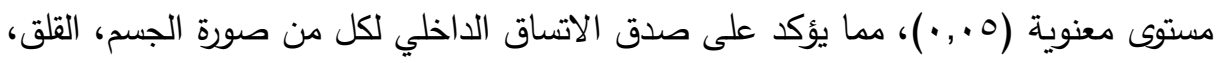

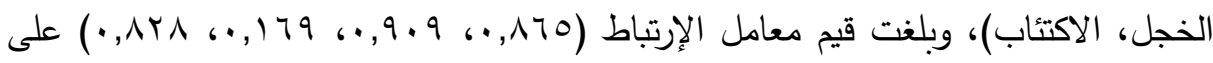
التوالي وهي قيم تؤكد على صدق المقياس. جدول (ץ): ثبات وصدق الاتساق الداخلى لمقياس المتغيرات الاجتماعية

\begin{tabular}{|c|c|c|c|}
\hline المغنوية & معامل ارتباط بيرسون & قيمة ألفا & أبعاد المقياس \\
\hline$\cdot,, .1$ & $\cdot, 00 \mathrm{r}$ & $\cdot, 70$ & العلاقات الاجتماعية \\
\hline,,$\ldots 1$ & $\cdot, 00 \mathrm{~V}$ & $\cdot, 771$ & الوصم الاجتماعي \\
\hline & & $\cdot, v \cdot r$ & الدرجة الكلية لمقياس المتغيرات الاجتماعية \\
\hline
\end{tabular}

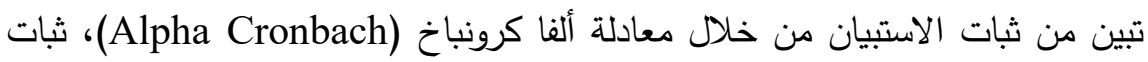

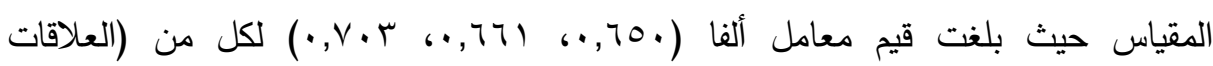
الاجتماعية، الوصم الاجتماعي، الدرجة الكلية لمقياس المتغيرات الاجتماعية) على التوالي، لهن،

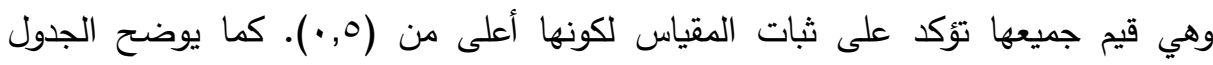
السابق أيضاً صدق الاتساق الداخلي السابق للمقياس وجد أن قيم معامل الارتباط دان دالة

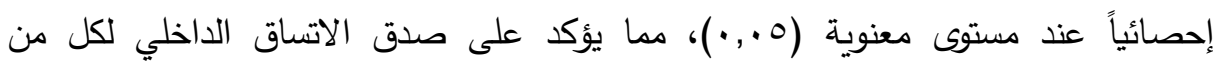

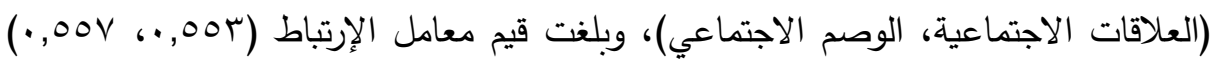
على التوالي وهي قيم تؤكد على صدق المقياس. 


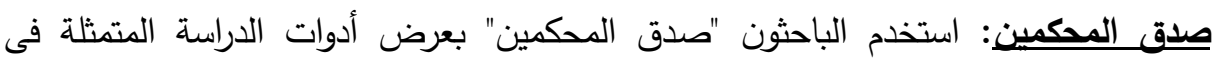

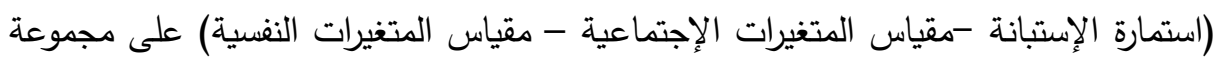

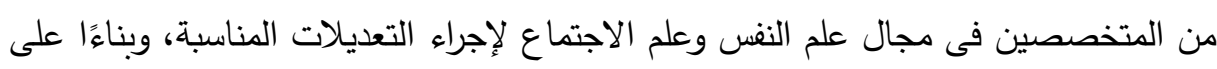
توجيهات المحكمين فقد تم إعادة صياغة بعض العبارات وحذف بعض الأن الأسئلة غير المناسبة لأبعاد المقاييس وإعادة ترتيب بعض الأسئلة، لتصبح مناسبة لتساؤلات وأهداف الدراسة ولتكون التهات العبارات صحيحة ومفهومة لـجتمع.

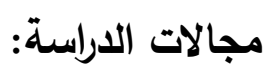

المجال البشري: يتكون إطار المعاينة من (·. (ب) السيدات والفتيات من سكان البيئات العشوائية والمخططة. المجال المكاني: تم إجراء الدراسة الميدانية (بعيادات ومراكز التجميل الجراحية) للسيدات والفتيات من ساكني البيئات العشوائية والمخططة (القاهرة - الجيزة - القليوبية)

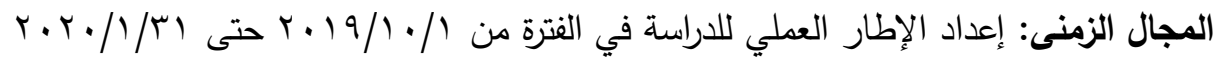

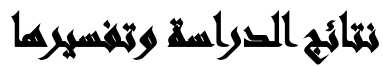

ينص التساؤل الأول على: الما اتِجَجاه السيدات نحو عمليات التجميل فى كل من البيئة

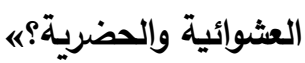
وللإجابة عن هذا التساؤل استخدت الدراسة الحالية المتوسطات الحسابية والانحرافات المعيارية، ويتضح ذلك من الجدول التالي: 
جدول (؛): يوضح المتوسطات الحسابية والانحرافات المعيارية لتطبيق استبانة اتجاه المرأة نحو عمليات التجميل على عينة الدراسة

\begin{tabular}{|c|c|c|c|c|c|c|c|c|c|}
\hline \multicolumn{3}{|c|}{ إجمالم العيذة } & \multicolumn{3}{|c|}{ بيئة المخططة } & \multicolumn{3}{|c|}{ 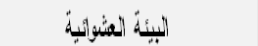 } & \multirow{2}{*}{ المنتفرات } \\
\hline الثوزن التسبب & $\xi$ & ? & الهزئ التببي & $\xi$ & ? & المئزن التهبب & $\xi$ & 2 & \\
\hline 91,90 & $\cdot, V$ & 9,9 & 9.4 & $\cdot, 79$ & 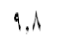 & 94,4 & $\cdot, 01$ & 9,94 & 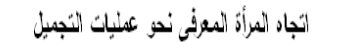 \\
\hline 99.18 &, 4 & ir & $1 .$. & $, \cdot, \cdot$ & ir & 99,8 &,, $4 \wedge$ & 11,9 & 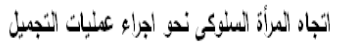 \\
\hline $99 . \%$ &., 0 & r... & 99.1 & $\cdot \pi$ & Y.A. & 99.1 & $\cdot, \mu \mathrm{V}$ & $Y 1 . A V$ & 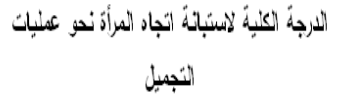 \\
\hline
\end{tabular}

يتبين من الجدول السابق لنتائج المتوسطات الحسابية والانحرافات المعيارية لاستبانة الآتِجَاه نحو عمليات التجميل على مجتمع الدراسة من وجهة المقيمين فى البيئة العشوائية وكنلك المقيمين فى بيئة مخططة ما يلي: المتوسط العام لإجمالي إجابات عينة الدراسة على عبارات الاستبانة: كان (Y),AV)

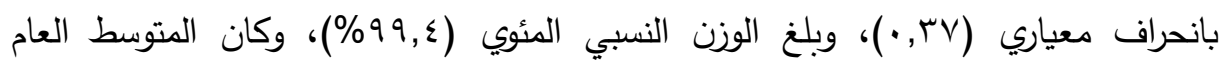

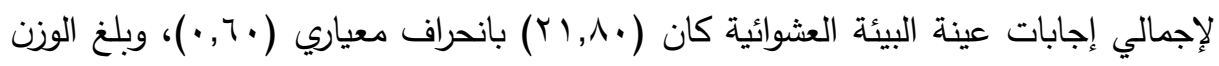

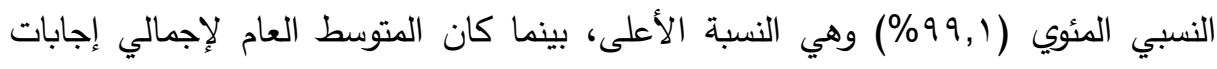

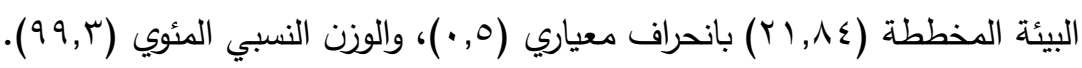

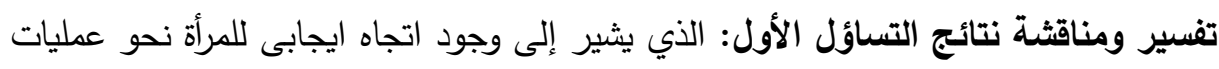

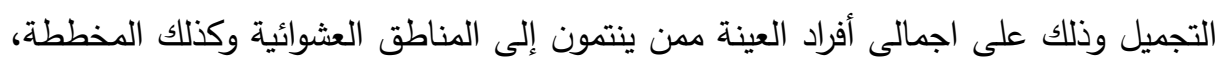

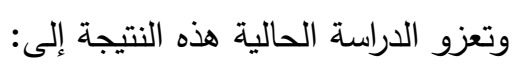

وجود اتجاه يتضمن الإدراك الذاتى واتجاهات قد تتعلق بعدم الرضا من قبل أفراد العينة

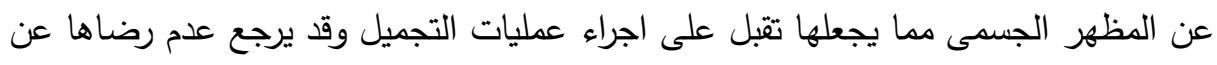
262

$$
\begin{aligned}
& \text { المجلد التاسع والأربعون، العدد الثامن، الجزء الخامس، أغسطس . r.r. }
\end{aligned}
$$

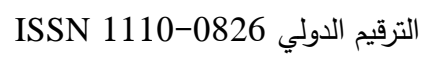


هذا المظهر الجسمى إلى بعض المتغيرات النفسية أو الإجتماعية التى تسعى الدراسة إلى ذاتى

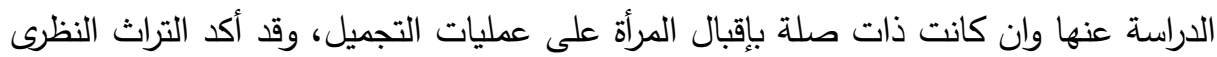
على أن عدم الرضا عن الجسم لدى الإنسان قد يترتب عليه الكثير من المشكلات النفسية

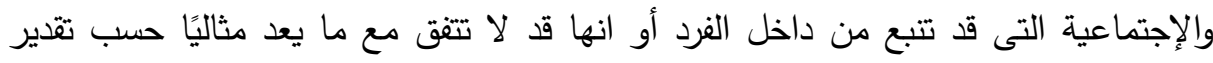

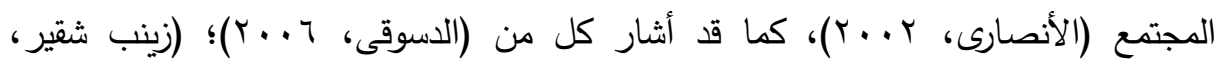

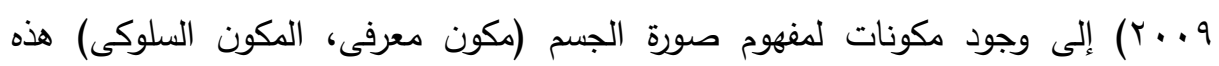
المكونات التى قد ترجعها الدراسة الحالية إلى وجود اتجاه ايجابى لدى المرأة نحو عمليات التجميل وهذه المكونات تتضمن الخصائص والصفات التى يدركها الفرد وخصائصه البدنية، وهو ما يسمى بالمكون المعرفى، كذلك تتضمن المشاعر والاتجاهات النفسية تجاه البدن سواء بالقبول أو الرفض أو عدم الرضا وهو ما يسمى بالمكون الوجدانى، وقد اتفقت نتيجة الدراسة

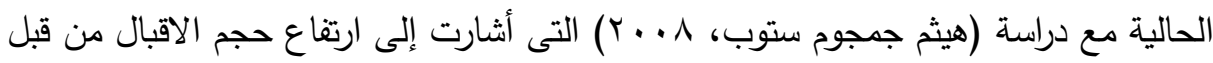

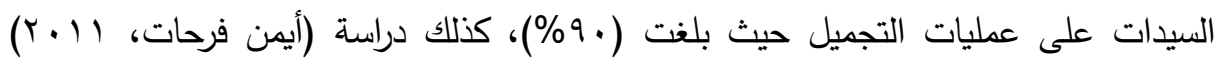

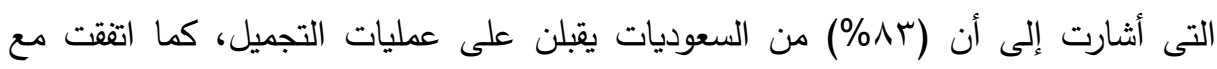

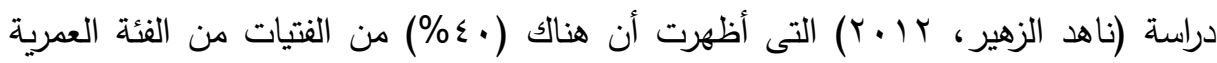

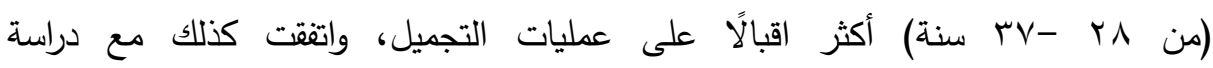
(al, Y. . 9 et Henderson)

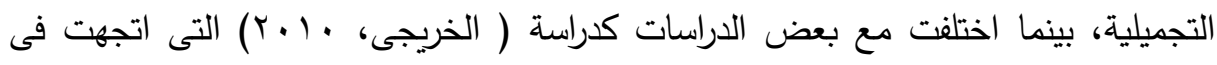

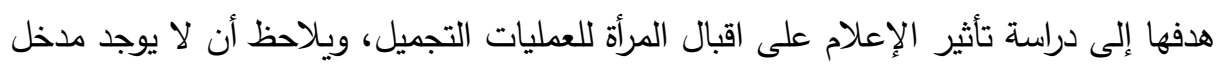

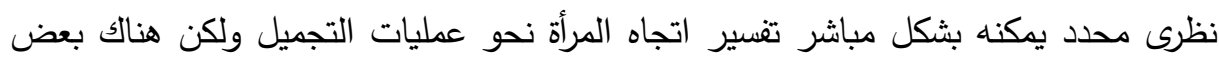

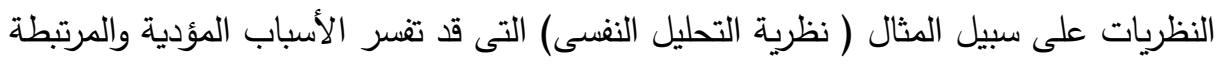

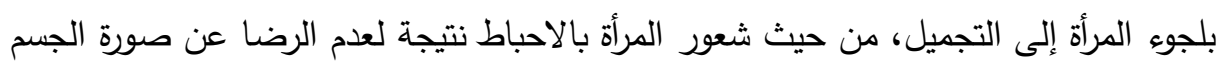




$$
\begin{aligned}
& \text { مجلة العلوم البيئية } \\
& \text { معهد الدراسات والبحوث البيئية - جامعة عين شمس له } \\
& \text { سامية محمود عبد المنعم وآخرون }
\end{aligned}
$$

وبالتلى إلى سوء تقدير الذات مما قد يجعلهن يتجهون إلى عمليات التجميل اشباعًا لتقديرهن

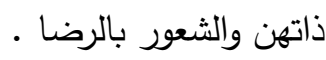
ينص التساؤل الثاني على: "هل توجد علاقة بين اتجاه المرأة نحو عمليات التجميل وبعض التصا

\begin{tabular}{|c|c|c|c|c|c|c|}
\hline \multicolumn{6}{|c|}{ الاتجاه نحو عمليات التجميل } & \multirow{4}{*}{ المتغيرات } \\
\hline \multicolumn{2}{|c|}{ الإجمالي } & \multicolumn{2}{|c|}{ بيئة مخططة } & \multicolumn{2}{|c|}{ بيئة عشوائية } & \\
\hline الدلالة & معامل & الدلالة & معامل & الدلالة & معامل & \\
\hline المعنوبـة & الارتباط & المعنوبة & الارتباط & المعنوبة & الارتباط & \\
\hline$\cdot, \varepsilon$ & $\cdot, \cdot 7 r-$ & $\cdot, \mathrm{V}$ & $\cdot, \cdot$ ro- & $\cdot, 0$ & $\cdot, \cdot 7 \varepsilon-$ & صورة الجسم \\
\hline$\cdot, 1$ & $\cdot, I Y Y-$ & $\cdot, 1$ & $\cdot, 10 \mathrm{r}-$ & $\cdot, \mathrm{V}$ & $\cdot, \cdot r V-$ & 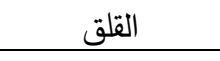 \\
\hline$\cdot, 0$ & $\cdot, .01-$ & $\cdot, r$ & $\cdot, 1 Y \varepsilon-$ & $\cdot, 0$ & $\cdot, \cdot V r-$ & 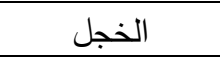 \\
\hline$\cdot, \cdots 1$ & $\begin{array}{c}- \\
* *, r q 9 \\
\end{array}$ & $\cdot, \cdots 1$ & $\begin{array}{c}- \\
* \text { r ror } \\
\end{array}$ & $\cdot, r$ & $\cdot, \| r-$ & الاكتئاب \\
\hline$\cdot, \cdot r$ & $\cdot, I V \cdot-$ & $\cdot, \cdot r$ & $*, Y \backslash \wedge-$ & $\cdot, \varepsilon$ & $\cdot .94-$ & 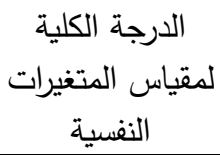 \\
\hline
\end{tabular}

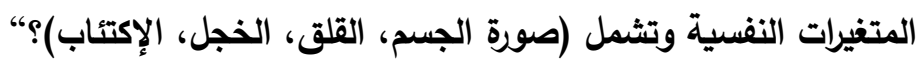

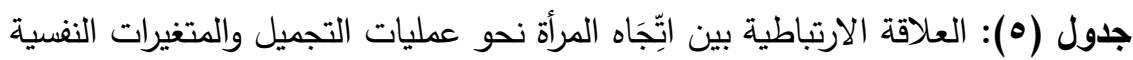

يتضح من الجدول السابق ما يلي: • توجد علاقة ارتباطية عكسية دالَّة إحصائًَا بين اتِّجَاه السيدات نحو عمليات التجميل وبين كل من بعد الاكتئاب والدرجة الكلية لمقياس المتغيرات النفسية لدى النساء إجمالي العينة،

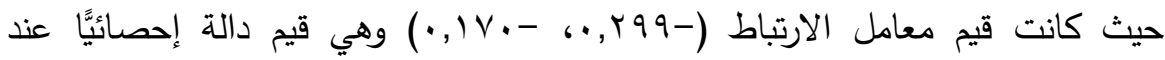

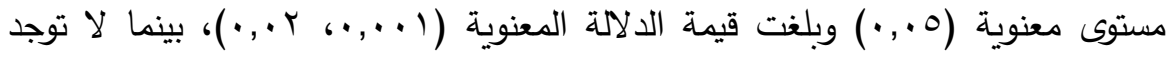
علاقة ارتباطية دالة إحصائيًا عند مستوى معنوية (0.,.•) بين مستوى التِجَاه النساء المقبلات على عمليات التجميل وكل من (صورة الجسم، القلق، الخجل) حيث كانت قيم إنياته 


$$
\begin{aligned}
& \text { مجلة العلوم البيئية } \\
& \text { معهد الدراسات والبحوث البيئية - جامعة عين شمس للئس }
\end{aligned}
$$

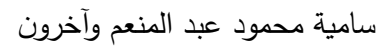

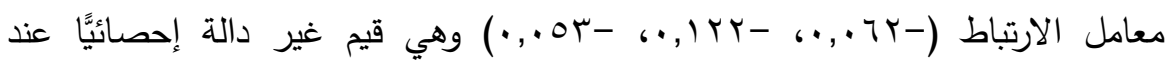

$$
\text { مستوى معنوية (0., . ). }
$$

• توجد علاقة ارتباطية عكسية دالَّة إحصائيَّا بين اتِجَّاه السيدات نحو عمليات التجميل وبين

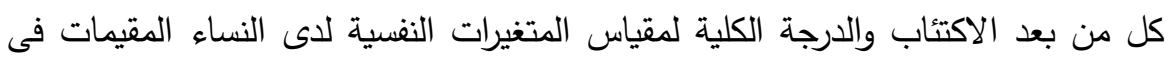

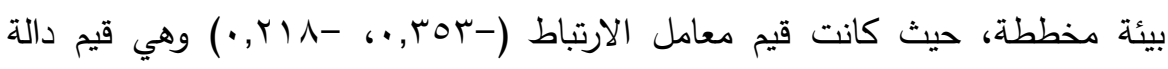

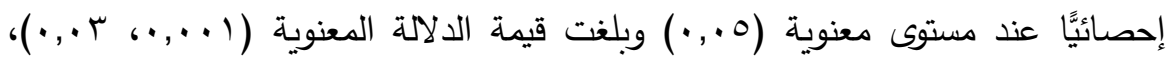

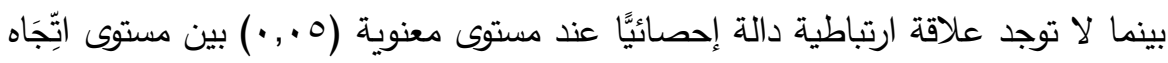

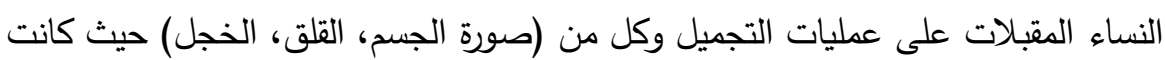

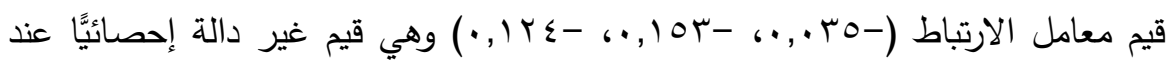

$$
\text { مستوى معنوية (0., (·). }
$$

•ال توجد علاقة ارتباطية دالَّة إحصائيًا بين اتِّجَاه السيدات نحو عمليات التجميل والمتغير

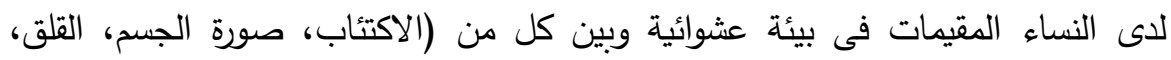

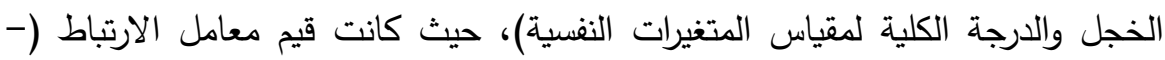

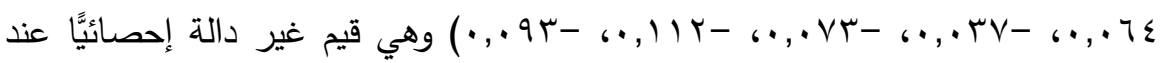

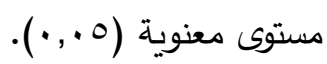


مجلة العلوم البيئية

معهد الدراسات والبحوث البيئية - جامعة عين شمس

سامية محمود عبد المنعم وآخرون

جدول (†): المتغيرات النفية واتجاه المرأة نحو عمليات التجميل

\begin{tabular}{|c|c|c|c|c|c|c|c|c|c|}
\hline \multicolumn{3}{|c|}{ إجمالي العينة (ن= . r) } & \multicolumn{3}{|c|}{ البيئة المخططة (ن= = 1) } & \multicolumn{3}{|c|}{ البيئة العشوائية (ن= - 1) } & \multirow[b]{2}{*}{ ال المتغيرات } \\
\hline المئوبي & $\varepsilon$ & p & النئوبي & $\varepsilon$ & p & المسئوي & $\varepsilon$ & p & \\
\hline$\checkmark \wedge, 0$ & $V, r$ & $Y \varepsilon, V$ & $V r, V$ & $\curlyvee, Y \wedge 0$ & $r q, 0 \leq$ & ה ג & $\vee, \imath \wedge$. & $r Y, Q \Lambda$ & الجسم \\
\hline$\uparrow \wedge, \varepsilon$ & $v, 0$ & $r \leq, 4$ & $V V, 0$ & $0,\{00$ & $r v, q)$ & $\Delta q, r$ & $v, \wedge \cdot Y$ & $r 1, r \leqslant$ & 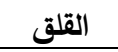 \\
\hline $74, V$ & $v, q$ & $r \leqslant,$. & 00,1 & $V, \leqslant \Psi \leqslant$ & $19, \wedge \varepsilon$ & $\vee \wedge, r$ & $0, \wedge 11$ & $r \Lambda, r$. & الخجل \\
\hline$T V, \Lambda$ & $\Lambda, r$ & $r \leqslant, \varepsilon$ & $\Lambda \cdot, \wedge$ & $0,9.1$ & rq, . & $0 \leqslant, q$ & $v, 79 Y$ & $19, v_{0}$ & الاكتئاب \\
\hline$q v, q$ & $r, r$ & $9 v, v$ & $\vee 1, \wedge$ & $1 \wedge, 7$ & $1, r, r v$ & $T \leqslant$, & $r, Y$ & $9 r, 1$. & المقلاية الملفية \\
\hline
\end{tabular}

يتضح من الجدول السابق ما يلي:

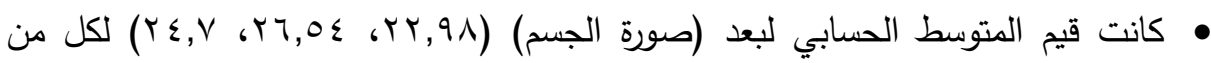

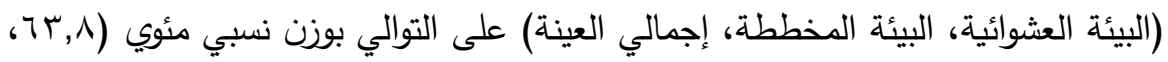

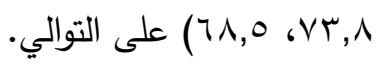

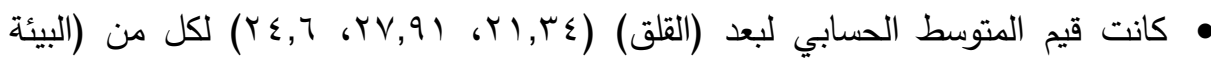

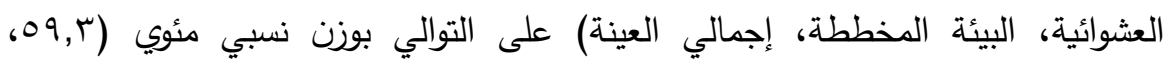

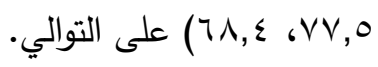

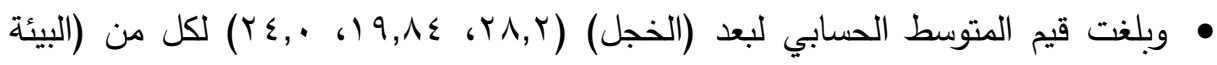

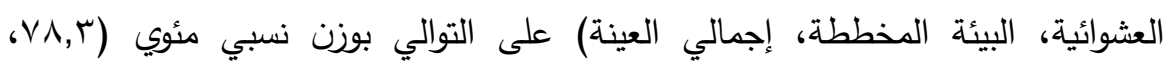

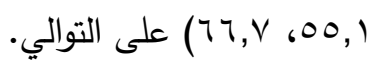




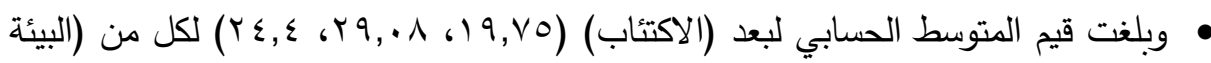

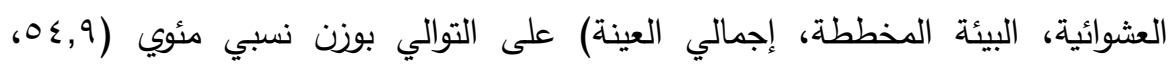

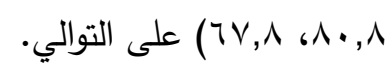

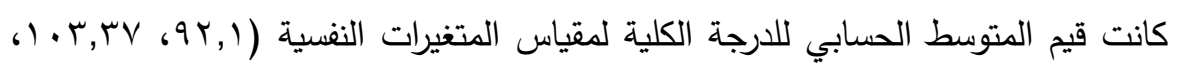

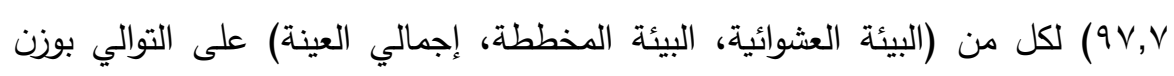

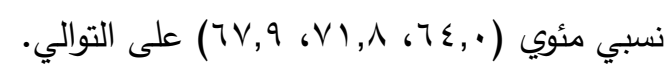
تفسير ومناقشة نتائج التساؤل الثانى: الذي يشير إلى وجود اتجاه ايجابي للاتجاه أفراد العينة نحو عمليات التجميل، وتعزو الدراسة الحالية هذه النتيجة إلى: • التجميل وبعض المتغيرات النفسية وتتضمن (صورة الجسم - التلق - الخجل - الاكتئاب) فلا شك أن الأفراد الذين يتمتعون بقدر وفير من الرضا الذاتي عن صورة أجسادهم هم أقل

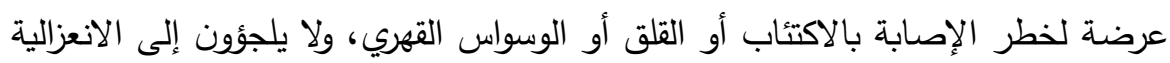

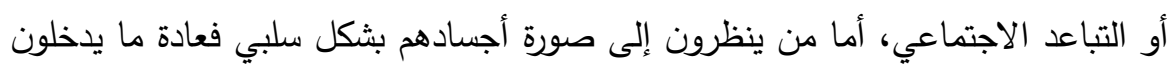

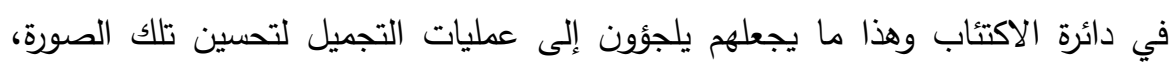

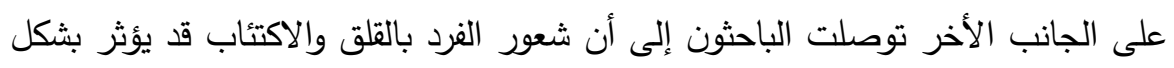

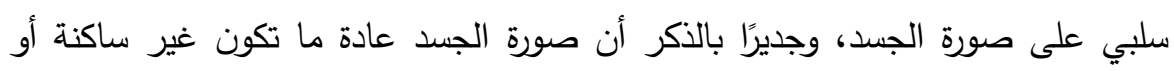

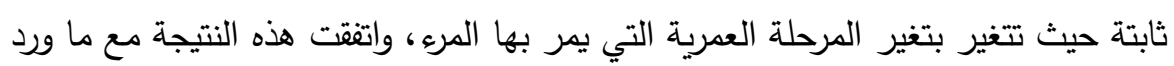

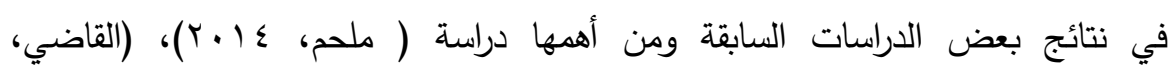

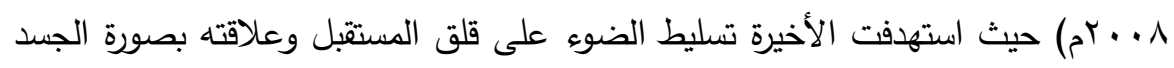

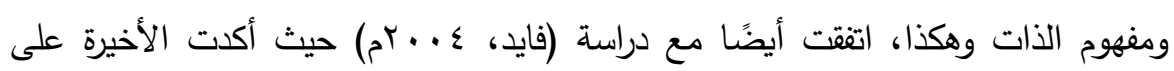
وجود علاقة جوهرية تجمع بين عدم الرضا عن صورة الجسد وعدم تكيف الفرد اجتماعيًا

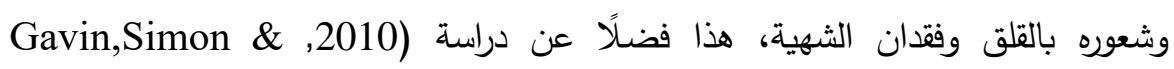

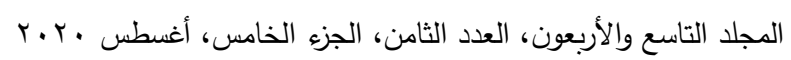

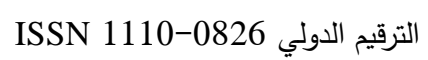


(Ludman حيث أكدت الدراسة الأخيرة على أن هناك علاقة بين السمنة المفرطة والثعور بالاكتئاب. • وكذلك اكدت (نظرية البيولوجية) التي تم وضعها من قبل " هنري هيد " واحدًا من أهم أطباء الأعصاب ويعد من أوائل العلماء الذين استخدموا تعبير صورة الجسد على على النتيجة

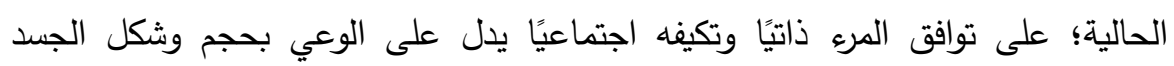

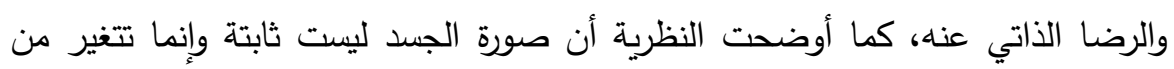

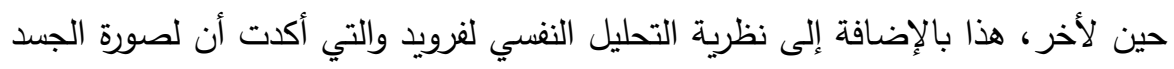

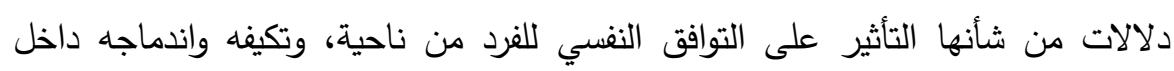

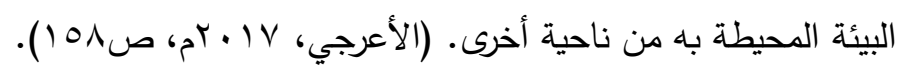

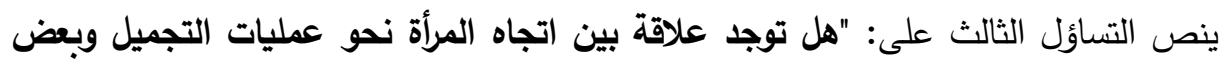

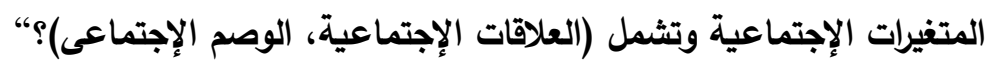

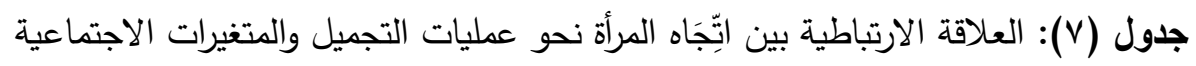

\begin{tabular}{|c|c|c|c|c|c|c|}
\hline \multicolumn{6}{|c|}{ الاتجاه نحو عمليات التجميل } & \multirow{4}{*}{ المتغيرات } \\
\hline \multicolumn{2}{|c|}{ الإجمالي } & \multicolumn{2}{|c|}{ بيئة مخططة } & \multicolumn{2}{|c|}{ بيئة عثوائية } & \\
\hline الدلالة & معامل & 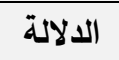 & معامل & الدلالة & معامل & \\
\hline المعنوبة & الارتباط & المعنوبة & الارتباط & المعنوبة & الارتباط & \\
\hline$\cdot, \cdots r$ & $\begin{array}{c}- \\
\cdots, Y_{1} \\
\end{array}$ & $\cdot, \cdots 1$ & **, & $\cdot, 7$ & $\begin{array}{c}- \\
., \text { or } \\
\end{array}$ & العلاقات الاجتماعية \\
\hline$\cdot, r$ & $\cdot, \cdot 91$ & $\cdot r$ & $\cdot, 1 \cdot 9$ & $\cdot, 9$ & $\begin{array}{c}- \\
\cdot, \cdot 11 \\
\end{array}$ & الوصم الاجتماعي \\
\hline$\cdot, r$ & $\cdot, 1,-$ & $\cdot, \cdot r$ & $*, 190-$ & $\cdot, 7$ & $\begin{array}{c}- \\
\cdot, .00 \\
\end{array}$ & الدرجة الكلية لمقياس الإتيرات \\
\hline
\end{tabular}


يتضح من الجدول السابق ما يلي:

- - توجد علاقة ارتباطية عكسية قوية دالَّة إحصائيَّا بين اتِّجَاه السيدات نحو عمليات التجميل

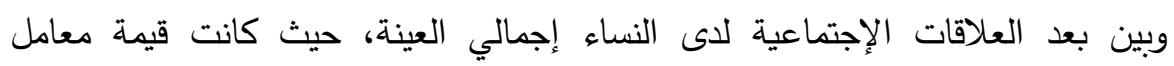

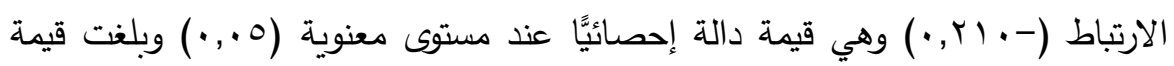

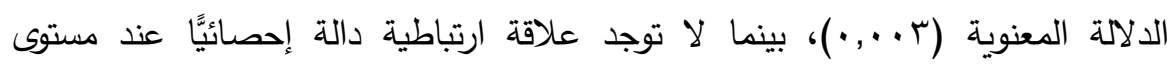
معنوية (0. . • ) بين مستوى اتِّجَاه النساء المقبلات على عمليات التجميل وكل من الوصم الاجتماعي والدرجة الكلية لمقياس المتغيرات الاجتماعية حيث كانت قيم معامل الارتباط لهاه

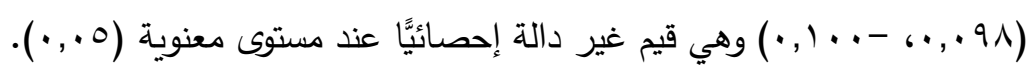

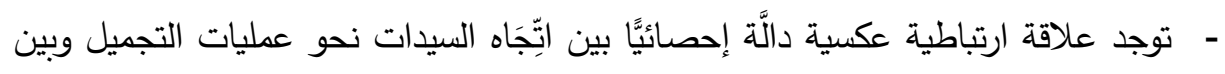
كل من بعد العلاقات الإجتماعية والدرجة الكلية لمقياس المتغيرات الاجتماعية لدى النساء

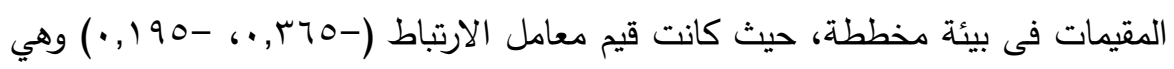

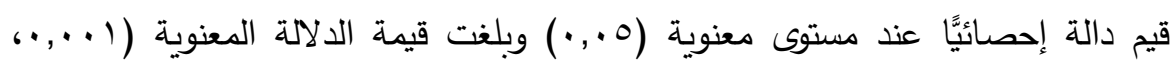

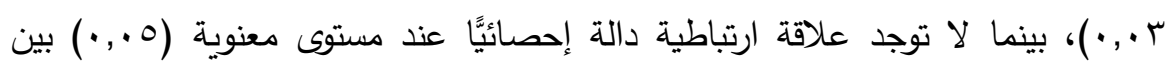

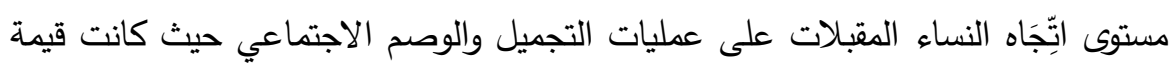
معامل الارتباط (9 • (, •) وهي قيمة غير دالة إحصائيًا عند مستوى معنوية (0. (. . •).

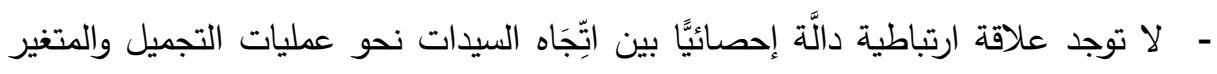

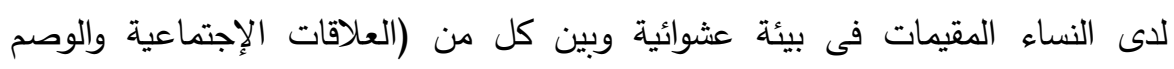

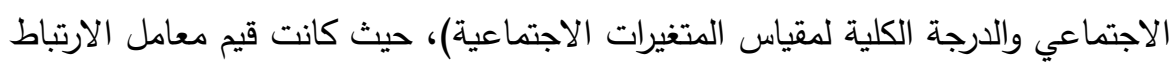

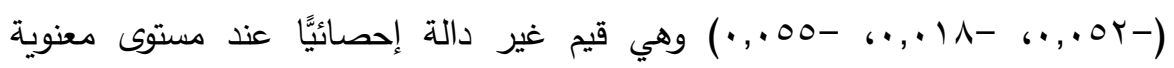

- - هل توجد علاقة بين اتجاه المرأة نحو عمليات التجميل وبعض المتغيرات الإجتماعية وتثمل (العلاقات الإجتماعية، الوصم الإجتماعى) لينى 
تفسير ومناقشة نتائج التساؤل الثالث: الذي يشير إلى وجود اتجاه ايجابي للاتجاه أفراد العينة

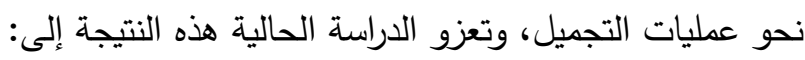

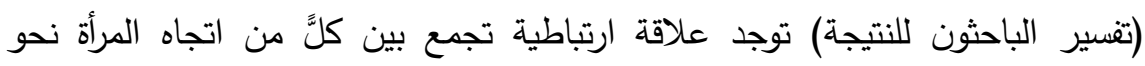

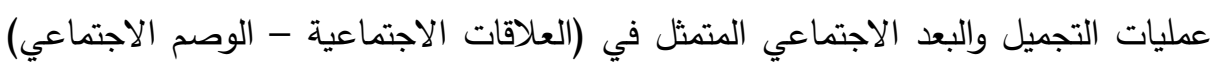

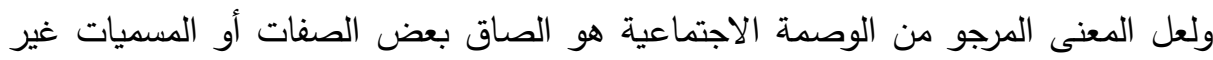

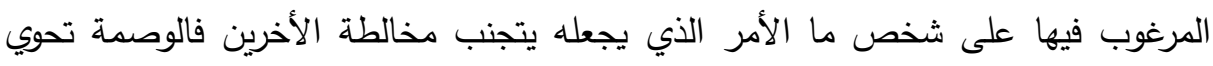

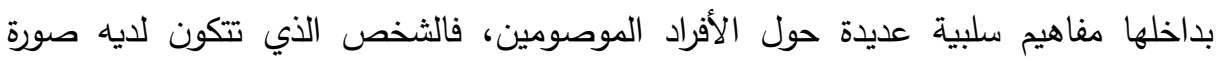
إدراكية سلبية حول جسده يثعر بالوصمة الاجتماعية، ومن هنا يتبين أن هناك علاقة وثيقة بين الذات الثخصية والذات الجسدية؛ حيث تؤثر كلَّ منهما على الأخر وتتأثر به.

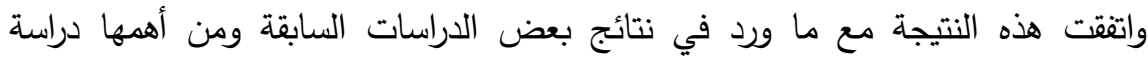

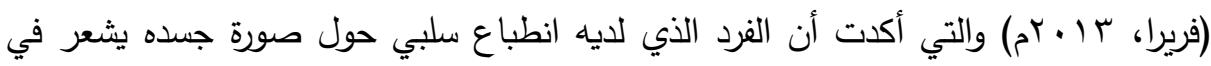
الكثير من الأحيان بالخجل، ولعل ذلك ما قد يدفعه نحو تجنب التفاعل الاجتماعي، وعدم

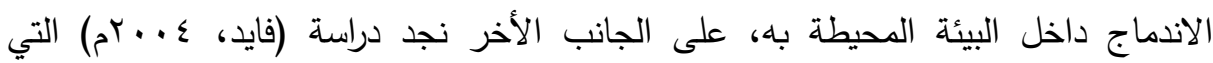

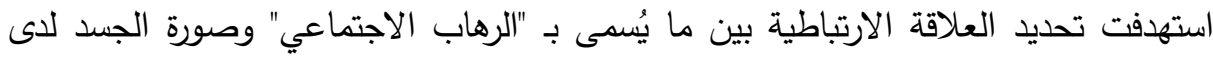

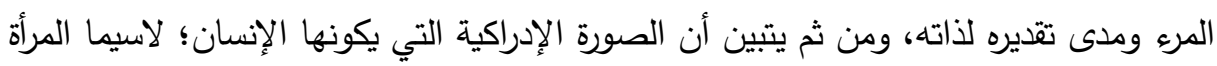

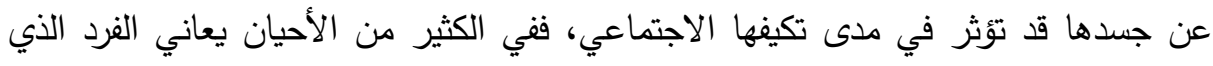

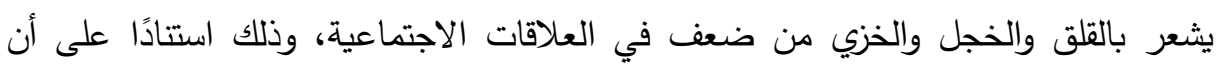
صورة الجسم السالبة ترتبط بثكل كبير بتقدير الذات وتوثر على اندماجه المجتمعي بشكل

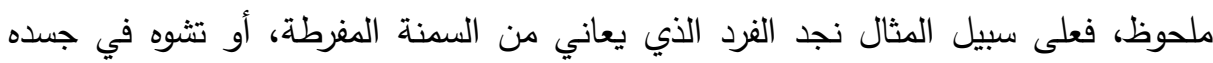
يتجنب الاختلاط بالناس خوفًا من النقد. وكذلك اكدت (نظرية الوصم الاجتماعي) لصاحبها "جوفمان" على مواجهة الفرد للكثير

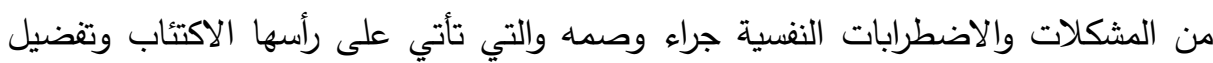
270

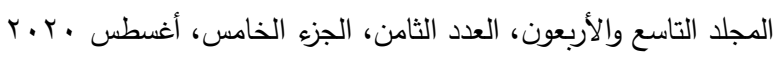

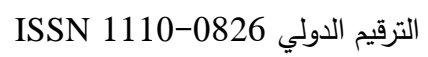


العزلة وعدم الاندماج أو التقاعل داخل مجتمعه، والمتمعن في ذلك الأمر يجد أن المره الذي

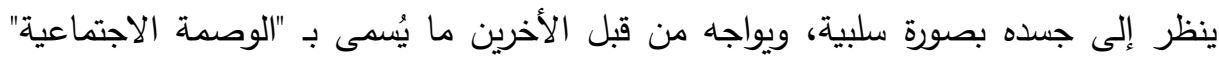

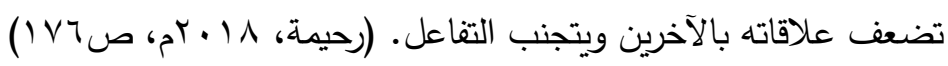

\section{الميوكياتي}

• تزويد المستثفيات والعيادات بمرشدين نفسيين لمساعدة النساء اللاتي يعانين من اضطرابات نفسية وذلك لعمل برامج إرشادية وعلاجية لمساعدتهن للوصول للجسم المثالي ومساعدتهن لتقبل ذواتهن. إرشاد النساء اللاتي يعانين من أفكار سلبية حول صورة أجسامهن ومحاولة مساعدتهن على التغلب على الصعوبات النفسية التي يواجهنها. قيام وزارة الصحة بأعداد البرامج التوعوية الصحية عبر وسائل الإعلام المختلفة لتوضيح الحالات التي تحتاج لعمليات التجميل الجراحية، والطرق السليمة في ذلك، وأهم المراكز والعيادات المتخصصة في إجراء العمليات التجميلية الجراحية.

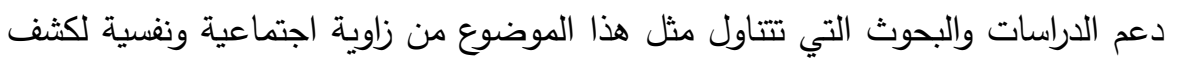

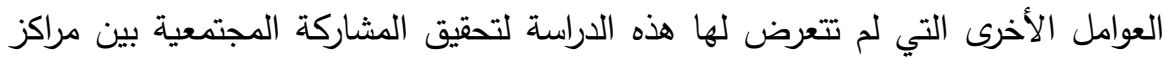
البحوث في الجامعات والمجتمع.

\section{المرالم}

ابراهيم، مايسة أحمد النيال (ع 99 ()): صورة الجسم وعلاقتها ببعض المتغيرات النفسية "دراسة

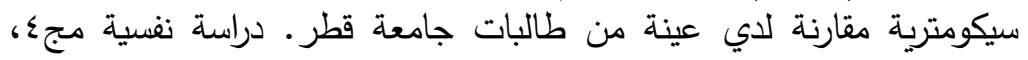

$$
\text { ع)، ص ا-ــ. }
$$

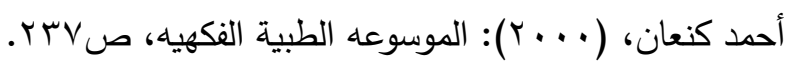

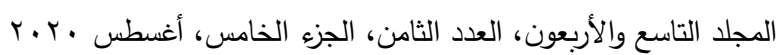

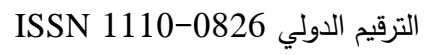


اسامه صباغ (999 (1)): العمليات التجميلية وحكمها في الشريعه الاسلاميه. دار ابن حزم،

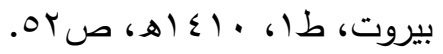

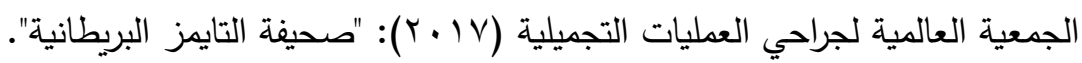

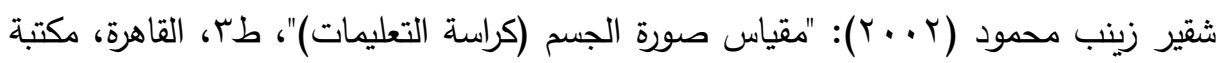

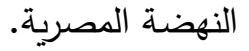

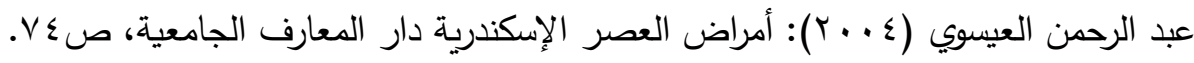
علي المحمدي (ך + . †): "فقه القضايا الطبيه المعاصرة".

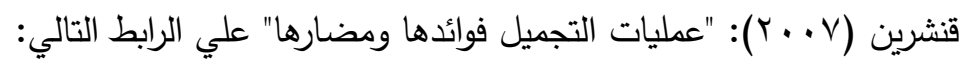

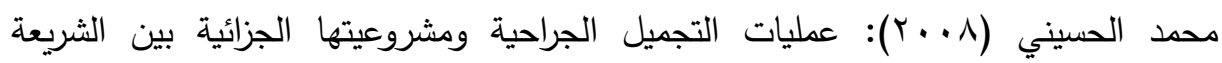

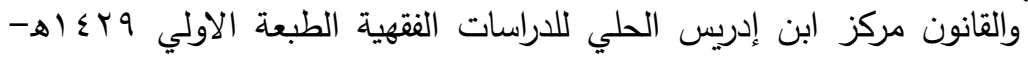

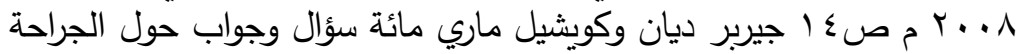

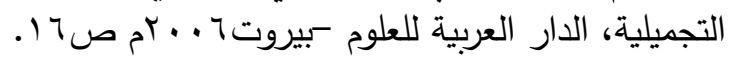

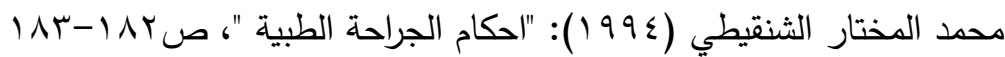
محمد خالد منصور (999 (1): الاحكام الطبيه المتعلقه بالنساء نقل عن الموسوعه الطبيه

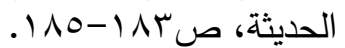

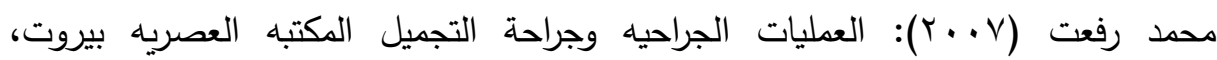
ص صr-10r

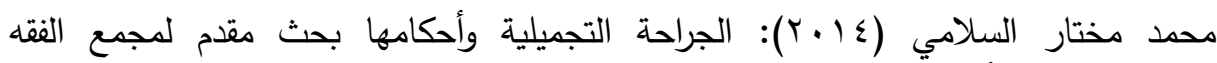

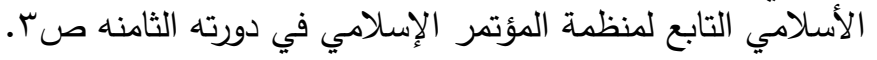
معجم المعاني الجامع وقاموس المعجم الوسيط. منظر الفضل (1990): المسئوليه الطبيه في الجراحه التجميلية، مكتبة دار الثقافه،

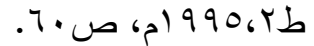

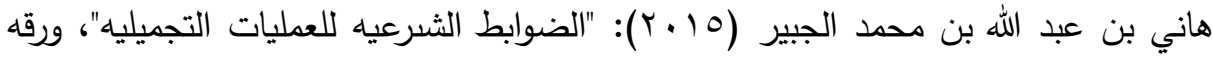

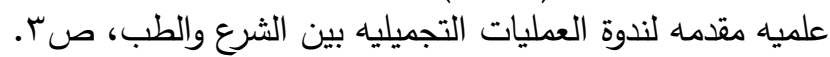




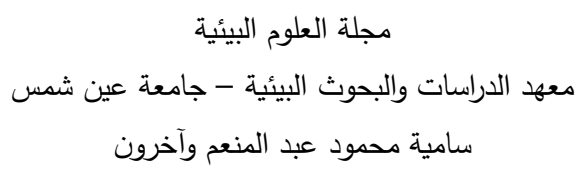

Ferreira, C. and Pinto, J. (2013): Self-compassion in the face of shame and body image dissatisfaction implications for eating disorders, Eating Behaviors. Voll4(2), pp207-210

Gavin, A. R.; Simon, G. E. and Ludman, E. J. (2010): The association between obesity, depression, and educational attainment in women: the mediating role of body image dissatisfaction. Journal of psychosomatic research.69, pp573-581.

Goldfield, G.S.; Moore, C.; Henderson, K.; Buchholz, A.; Obeid, N. and Flament, M. F. (2010): Body dissatisfaction, dietary, restraint, depression and weight status in adolescents. Journal of school, health, Vol.80. No.4, pp186-192.

\title{
SOCIAL AND PSYCHOLOGICAL CHANGES ASSOCIATED WITH WOMEN'S PLASTIC SURGERY A STUDY IN DIFFERENT ENVIRONMENTS
}

\author{
Samiah M. Abdel Menem(1); Mustafa I. Awad(2) \\ Ayman A. Shaker ${ }^{(3)}$ and Al - Shaimaa B. Amer ${ }^{(2)}$
}

1) Post graduate student at Institute of Environmental Studies \& Research, Ain Shams University 2) Institute of Environmental Studies $\&$ Research, Ain Shams University 3) Faculty of Medicine, Ain Shams University

\section{ABSTRACT}

This study aimed to identify the social and psychological changes associated with women's plastic surgery, and this study was made on (200) women who live in rural and urban areas. The choice was made

$$
\begin{aligned}
& \text { المجلد التاسع والأربعون، العدد الثامن، الجزء الخامس، أغسطس . r. }
\end{aligned}
$$

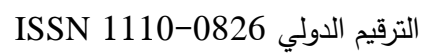




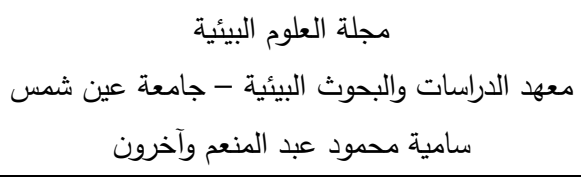

based on the approval of the participants who frequently visit (clinics and plastic surgery centers). The study consisted of the survey sample, and this survey study was made on a sample of (40) individuals in order to answer (40) questionnaires that were returned in full, to ensure the validity and consistency of the test, and the researcher used the descriptive analytical method and field study method to collect information and data. By using the questionnaire as a tool for collecting data about the study, so the questionnaire is defined as a set of written questions that are developed with the intention of obtaining information and opinions of the respondents about a specific phenomenon or topic and one of the most important features of the questionnaire is to save a lot of time and effort on the researcher. In addition to using the psychometric properties of the measuring instrument to ensure that the study tool used can measure what was set for it to measure, the psychometric properties of this tool must be measured.

The research has reached some results, the most important of which is the existence of an inverse correlation between the trend of women towards plastic surgery and between each dimension of depression and the overall degree of the scale of psychological variables among women residing in a planned environment. A random environment between each of (depression, body image, anxiety, shyness, and the overall degree of psychological changes).

The study also recommended a set of recommendations, the most important of which is the need for the Ministry of Health to prepare health awareness programs throughout various media outlets and the need to support studies and research that address such a topic. From a social and psychological point of view to reveal other factors that this study did not cover, to achieve societal participation between research centers in universities and society.

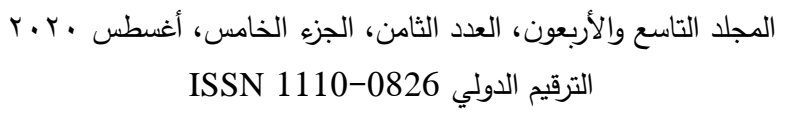

